\title{
Consequences of Oxidative Stress on Plant Glycolytic and Respiratory Metabolism
}

\author{
Sébastien Dumont and Jean Rivoal* \\ Institut de Recherche en Biologie Végétale, Département de Sciences Biologiques, Université de Montréal, Montreal, QC, \\ Canada
}

OPEN ACCESS

Edited by:

Miguel Angel Ballicora, Loyola University Chicago,

United States

Reviewed by:

Robert D. Hancock,

James Hutton Institute,

United Kingdom

Nishikant Wase,

University of Nebraska-Lincoln,

United States

*Correspondence:

Jean Rivoal

jean.rivoal@umontreal.ca

Specialty section:

This article was submitted to

Plant Metabolism

and Chemodiversity,

a section of the journal

Frontiers in Plant Science

Received: 22 October 2018

Accepted: 31 January 2019

Published: 18 February 2019

Citation:

Dumont S and Rivoal J (2019) Consequences of Oxidative Stress on

Plant Glycolytic and Respiratory

Metabolism. Front. Plant Sci. 10:166.

doi: $10.3389 /$ fpls.2019.00166
Reactive oxygen species (ROS) and reactive nitrogen species (RNS) are present at low and controlled levels under normal conditions. These reactive molecules can increase to high levels under various biotic and abiotic conditions, resulting in perturbation of the cellular redox state that can ultimately lead to oxidative or nitrosative stress. In this review, we analyze the various effects that result from alterations of redox homeostasis on plant glycolytic pathway and tricarboxylic acid (TCA) cycle. Most documented modifications caused by ROS or RNS are due to the presence of redox-sensitive cysteine thiol groups in proteins. Redox modifications include Cys oxidation, disulfide bond formation, S-glutathionylation, S-nitrosylation, and S-sulfhydration. A growing number of proteomic surveys and biochemical studies document the occurrence of ROS- or RNS-mediated modification in enzymes of glycolysis and the TCA cycle. In a few cases, these modifications have been shown to affect enzyme activity, suggesting an operational regulatory mechanism in vivo. Further changes induced by oxidative stress conditions include the proposed redox-dependent modifications in the subcellular distribution of a putative redox sensor, NAD-glyceraldehyde-3P dehydrogenase and the micro-compartmentation of cytosolic glycolytic enzymes. Data from the literature indicate that oxidative stress may induce complex changes in metabolite pools in central carbon metabolism. This information is discussed in the context of our understanding of plant metabolic response to oxidative stress.

\footnotetext{
Keywords: oxidative stress, glycolysis, respiration, TCA cycle, redox post-translational modifications, $S$-glutathionylation, $S$-nitrosylation, plant
}

Abbreviations: ACO, aconitase; ADH, alcohol dehydrogenase; ASC, ascorbate; BI-1, Bax inhibitor-1; BioGEE, biotinylated glutathione ethyl ester; BioGSSG, biotinylated oxidized glutathione; BSO, buthionine-(S,R)-sulfoximine; Cd, cadmium; cTPI, cytosolic triosephosphate isomerase; DHS, dihydrosphingosine; DTT, dithiothréitol; ENO, enolase; ESI-MS, electrospray ionization mass spectrometry; ETC, electron transport chains; FBA, fructose-bisphosphate aldolase; FUM, fumarase; GapC1/C2, cytosolic GAPDH isoforms; GAPDH, GAP dehydrogenase; GRX, glutaredoxin; GRXC1, glutaredoxin C1; GRXC2, glutaredoxin C2; GSH, reduced glutathione; GSNO, S-nitrosoglutathione; GSSG, oxidized glutathione; $\mathrm{H}_{2} \mathrm{O}_{2}$, hydrogen peroxide; $\mathrm{H}_{2} \mathrm{~S}$, hydrogen sulfide; IDH, isocitrate dehydrogenase; KO, knock-out; LC-MS/MS, liquid chromatography-tandem mass spectrometry; $\mathrm{MDH}$, malate dehydrogenase; NaHS, sodium hydrosulfide; NO, nitric oxide; PLD $\delta$, phospholipase D, PPP, pentose phosphate pathway; PTM, post-translational modification; RNS, reactive nitrogen species; ROS, reactive oxygen species; SnRK1, sucrose non-fermenting 1-related protein kinase; TCA, tricarboxylic acid; TRX, thioredoxin; VDAC, voltage-dependent anion channel. 


\section{INTRODUCTION}

In this review, we examine the effects of oxidative stress on enzymes from glycolysis and the TCA cycle and discuss its impact on various aspects of plant non-photosynthetic carbon metabolism. In recent years, a number of studies have addressed the impact of oxidative stress conditions on plant metabolism. Several proteomic surveys aimed at identifying different types of protein redox modification have also identified enzymes related to carbon metabolism that are targeted by these modifications (Zaffagnini et al., 2012a; Hu et al., 2015; Aroca et al., 2017a). Redox regulation of chloroplastic enzymes form Calvin-Benson cycle has been the subject of several reviews (Ruelland and Miginiac-Maslow, 1999; Buchanan et al., 2002; Michelet et al., 2013). Redox regulation of starch metabolic enzymes has also been evaluated lately (Skryhan et al., 2018). However, the general impact of redox modifications on enzymes from plant glycolytic and respiratory metabolism and on the activity of these pathways has not been assessed recently. Our review first considers protein redox modifications induced by ROS and RNS, as well as antioxidant strategies developed by plants. We then examine the effects of oxidative modifications on glycolytic TCA cycle enzymes to highlight some recent advances. We also discuss the redox regulation of these pathways while addressing other consequences of oxidative stress on these enzymes such as changes in localization, formation of protein complexes and moonlighting properties.

\section{Origin of Reactive Oxygen Species, Reactive Nitrogen Species, and Hydrogen Sulfide}

Reactive oxygen species and RNS are present in plant cells in normal conditions, mainly as by-products of aerobic and photosynthetic metabolism (Tripathy and Oelmüller, 2012). An elevation in ROS and RNS concentrations resulting from the exposure of plants to several biotic and abiotic stresses is also well documented (Airaki et al., 2012; Marino et al., 2012; Romero-Puertas et al., 2013; del Rio, 2015; Demidchik, 2015; Domingos et al., 2015; You and Chan, 2015; AbdElgawad et al., 2016; Camejo et al., 2016). Oxidative stress is caused by such increase in ROS levels leading to the generation of superoxide anion $\left(\mathrm{O}_{2}^{-\bullet}\right), \mathrm{H}_{2} \mathrm{O}_{2}$, and hydroxyl radical $\left(\mathrm{OH}^{\bullet}\right)$ (Thannickal and Fanburg, 2000; Sies et al., 2017). Nitrosative stress is caused by elevated levels of RNS such as NO, peroxynitrite $\left(\mathrm{ONOO}^{-}\right)$and nitrosoglutathione (GSNO) (Sies et al., 2017; Umbreen et al., 2018). Imbalance in ROS and RNS concentrations during stress can lead to various types of damage to cell macromolecules, including proteins (Apel and Hirt, 2004; Møller et al., 2007; Foyer and Noctor, 2009; Corpas et al., 2011).

In plants, ROS can be generated by the ETC in chloroplasts and mitochondria. Membrane-localized NADPH oxidases are also known as ROS producers during plant development and in response to stress (Marino et al., 2012). GSH is known to be involved in redox buffering (see below), but is also known for its ability to form disulfide bridges with sensitive protein Cys residues resulting in a redox PTM named S-glutathionylation (Figure 1) (Zaffagnini et al., 2012c). NO can be produced in mitochondria through the reduction of $\mathrm{NO}_{2}{ }^{-}$by the mitochondrial ETC and possibly via nitrite and arginine dependent pathways (Gupta and Kaiser, 2010; Igamberdiev et al., 2010; Zaffagnini et al., 2016). Nitrosoglutathione (GSNO)/GSNO reductase system, peroxiredoxins, TRXs, and pathogens- and hypoxically induced non-symbiotic hemoglobin are known to participate in the control of NO (Dordas et al., 2003a,b, 2004; Seregélyes et al., 2003; Bailey-Serres and Voesenek, 2008; Gupta and Igamberdiev, 2011; Zaffagnini et al., 2016).

Hydrogen sulfide is a gaseous signaling molecule found in both plants and animals. In plants, $\mathrm{H}_{2} \mathrm{~S}$ is produced by the sulfur assimilation pathway and L-/D-cysteine degradation (Fu et al., 2018). High levels of $\mathrm{H}_{2} \mathrm{~S}$ can be phytotoxic, but at lower concentrations, $\mathrm{H}_{2} \mathrm{~S}$ was demonstrated to play several roles during plant growth and development as well as biotic and abiotic stress response (Zhang et al., 2008; Chen et al., 2011; Shen et al., 2012, 2013). As opposed to ROS and RNS, $\mathrm{H}_{2} \mathrm{~S}$ is not an electrophilic molecule that spontaneously reacts with reduced thiol groups. However, $\mathrm{H}_{2} \mathrm{~S}$ can react with oxidized thiols leading to protein $S$-sulfhydration (also named persulfidation) (Figure 1) (Paul and Snyder, 2012).

\section{Antioxidant Strategies in Plants}

In order to cope with oxidative stress, plants have developed several enzymatic and non-enzymatic strategies to scavenge free ROS in cells. Today, these mechanisms are well known and have been extensively reviewed (Mittler, 2002; Gill and Tuteja, 2010; Sharma et al., 2012). Non-enzymatic strategies depend on small molecules such as membrane localized $\alpha$-tocopherols which can play essential antioxidant functions by acting as "sacrificial chemical scavengers" (Fryer, 1992), leading to the removal of ROS molecules through oxidation of $\alpha$-tocopherols. Plastid localized carotenoids also protect plant cells from oxidative stress similarly to $\alpha$-tocopherols (Larson, 1988; Mittler, 2002). The amino acid Pro is known to be induced by oxidative stress and has been shown to have a positive effect on antioxidant enzymes in plants (Ozturk and Demir, 2002). It has also been demonstrated that Pro can scavenge hydroxyl radicals, suggesting an important role of this amino acid in tolerance to oxidative stress (Smirnoff and Cumbes, 1989; Gill and Tuteja, 2010). Plants also accumulate other antioxidant molecules such as flavonoids (Hernandez et al., 2009) and polyamines (Groppa et al., 2001) that were shown to increase tolerance to several environmental stresses. Small redox active molecules such as ASC and the Cys-containing tripeptide GSH can also be used with specific peroxidase systems for ROS removal. Once oxidized, ASC and GSH can be recycled to their reduced form by reductases systems using NADPH as reductive power (Noctor et al., 2017).

Antioxidant enzymes and enzymatic-dependent mechanisms also control ROS levels in plant cells. Superoxide dismutase is a metalloenzyme responsible for the detoxification of superoxide anion leading to the formation of $\mathrm{H}_{2} \mathrm{O}_{2}$ and $\mathrm{O}_{2}$ (Alscher 


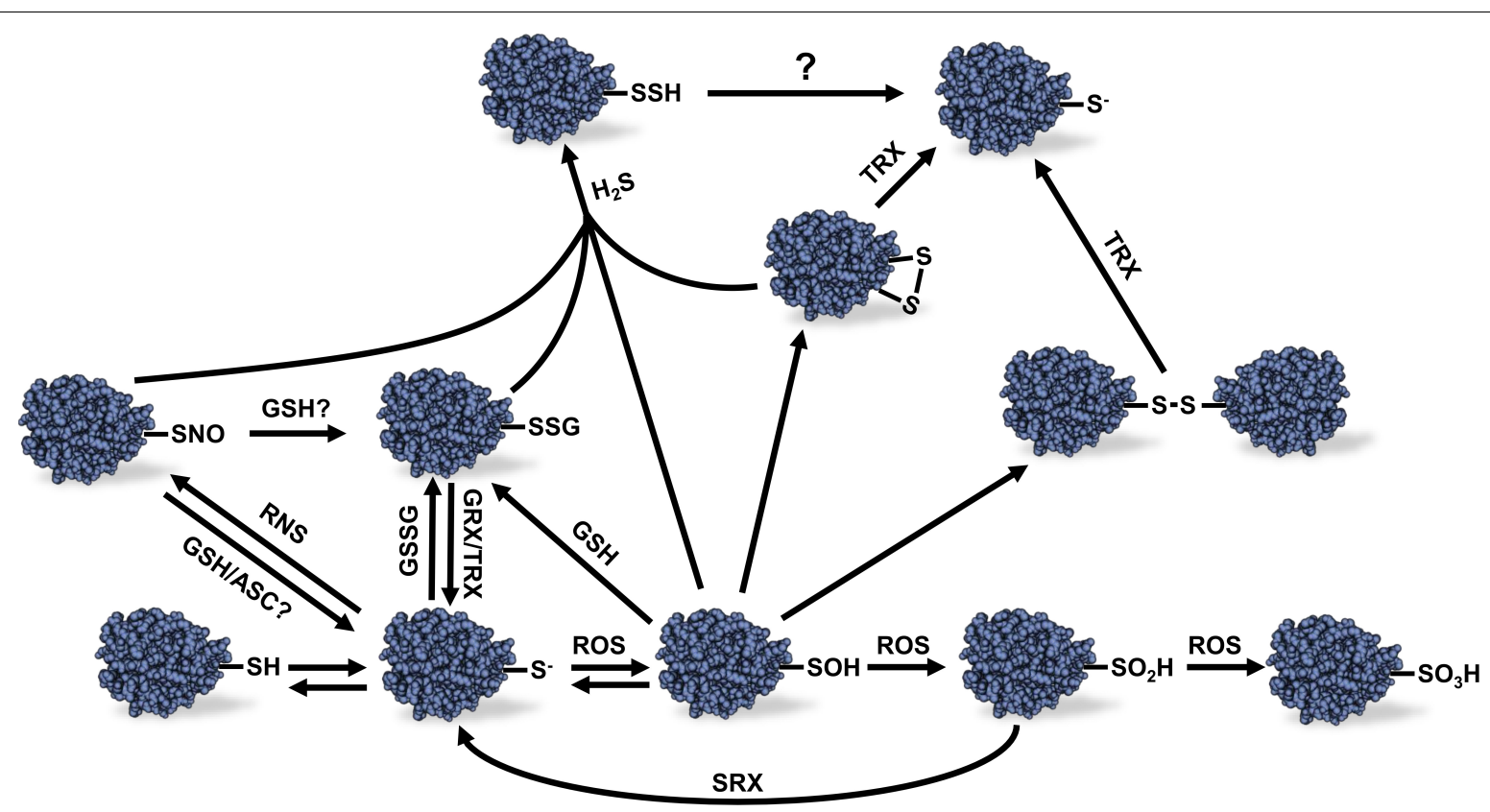

FIGURE 1 | Different redox modifications of protein Cys thiols and their reversibility. Protein thiol oxidation can lead to a variety of redox modifications. The scheme presents the relations between the different redox modifications and the reversibility of these modifications. Sulfonic acid $\left(-\mathrm{SO}_{3} \mathrm{H}\right)$ formation is considered to be irreversible as well as sulfinic acid $\left(-\mathrm{SO}_{2} \mathrm{H}\right)$ except in the case of certain peroxiredoxins which sulfinic acid Cys residue can be reduced by sulfiredoxin using and ATP-dependent mechanism. See text for details. ROS, reactive oxygen species; RNS, reactive nitrogen species; $\mathrm{H}_{2} \mathrm{~S}$, hydrogen sulfide; GSSG, oxidized glutathione; GSH, reduced glutathione; ASC, ascorbate; GRX, glutaredoxin; TRX, thioredoxin; SRX, sulfiredoxin; R-SH, reduced thiol; R-S ${ }^{-}$, thiolate anion; R-SOH, sulfenic acid; R-SNO, protein S-nitrosylation; R-SSG, protein S-glutathionylation Cys; R-SSH, protein S-sulfhydration; R-SS-R, disulfide bond.

et al., 2002). $\mathrm{H}_{2} \mathrm{O}_{2}$ can be metabolized by several antioxidant enzymes such as catalase, ASC peroxidase (APX), glutathione peroxidase (GPX) and peroxiredoxins (PRXs). As opposed to different kind of peroxidases, catalase does not require reductant to detoxify $\mathrm{H}_{2} \mathrm{O}_{2}$ (Mhamdi et al., 2010). The $\mathrm{H}_{2} \mathrm{O}_{2}$ metabolizing enzyme APX catalyzes the first step of the ASC-GSH cycle. In this process, ASC is oxidized to dehydroascorbate (DHA) by APX to detoxify $\mathrm{H}_{2} \mathrm{O}_{2}$. DHA is then recycled by a DHA reductase using GSH as reducing power, thus producing GSSG. The latter is reduced back to GSH by GSH reductase using NADPH as a reductant (Noctor and Foyer, 1998). Similarly, to APX, GPX can detoxify $\mathrm{H}_{2} \mathrm{O}_{2}$ but using directly GSH instead of ASC as reducing power (Margis et al., 2008). Like APX and GPX, PRXs metabolize organic hydroperoxides such as $\mathrm{H}_{2} \mathrm{O}_{2}$. PRXs use Cys residues in their protein sequence as reducing power for their enzymatic activity. Briefly, PRXs react with $\mathrm{H}_{2} \mathrm{O}_{2}$ via a catalytic Cys residue which becomes oxidized leading to the formation of inter- or intra-molecular disulfide bond depending on their type (Dietz, 2003). Some PRXs can also form a disulfide bond with glutathione (NogueraMazon et al., 2006). Once oxidized under disulfide form, PRXs are reduced back by a disulfide reductase system such as TRXs or GRXs.

\section{Cys Oxidation by ROS Molecules}

Despite the presence of antioxidant systems in plant cells, ROS can increase to potentially harmful levels in specific conditions leading to oxidative stress. Protein Cys residues are major targets of redox modifications due to the chemical properties of the sulfur atom present in thiol groups (Figure 1). Protonated thiol groups display a lower sensitivity to oxidation by electrophilic molecules like ROS than the deprotonated thiolate anion form. Usually, Cys thiols tend to stay mostly protonated in physiological conditions due to their $\mathrm{p} K_{a}$ around 8.5-9.0. However, the $\mathrm{p} K_{a}$ of some Cys residues can be lowered when the thiol group is sterically near the side chain of basic amino acids such as Arg, Lys, or His; as well as in the proximity of metal ions, alpha helices dipole or specific $\mathrm{H}$-bonding in the $3 \mathrm{D}$ structure of the protein (Britto et al., 2002; Barford, 2004; Zaffagnini et al., 2012c). These conditions will promote deprotonation of thiol groups and stabilize the thiolate anion form making these Cys residues more nucleophilic, therefore more reactive toward ROS (Finkel, 2000; Choi et al., 2001). Cys oxidation by ROS leads to the formation of a sulfenic acid. This latter group is highly unstable and can be further oxidized to sulfinic acid (R$\mathrm{SO}_{2} \mathrm{H}$ ) and sulfonic acid $\left(\mathrm{R}-\mathrm{SO}_{3} \mathrm{H}\right)$ (Figure 1). In most cases, these latter modifications are considered to be non-reversible in vivo (Ghezzi and Bonetto, 2003; Forman et al., 2010) except for some reported PRXs for which Cys sulfinic acid could be reduced by a sulfiredoxin using an ATP-dependent mechanism (Chang et al., 2004; Woo et al., 2005). Sulfenic acid can also react with a reduced thiol group to form intra- or inter-protein disulfide bonds, or a disulfide bond with GSH leading to protein S-glutathionylation (Figure 1). These redox PTMs can be reversed in vitro by addition of 
reductants such as dithiothreitol (DTT) or in vivo by specific oxidoreductases such as TRXs or GRXs (Poole et al., 2004; Zaffagnini et al., 2012c).

\section{Protein S-Glutathionylation, S-Nitrosylation, and S-Sulfhydration}

Protein S-glutathionylation can prevent unwanted disulfide bonds, aggregates and irreversible Cys oxidation in cells by promoting spontaneous disulfide bond formation between protein sulfenic acid Cys and glutathione (Rouhier et al., 2008; Zaffagnini et al., 2012c). Protein S-glutathionylation can also occur spontaneously by reaction of a reduced Cys residue with GSSG (Figure 1). However, due to the high GSH:GSSG ratio in the cytosol and mitochondria, $S$-glutathionylation by thiol disulfide exchange in these compartments seems unlikely to happen in vivo unless during exposure to severe oxidative stress conditions (Meyer et al., 2007; Schwarzländer et al., 2008). Interestingly, addition of GRXC2 was shown to accelerate A. thaliana BRI1-associated receptor-like kinase 1 inhibition by GSSG in vitro suggesting a first, and still unique, example of S-glutathionylation catalysis in plants (Bender et al., 2015). The reverse reaction of protein $S$-glutathionylation is called deglutathionylation (Figure 1). While some TRXs were shown to be able to perform deglutathionylation reactions in vitro, their efficiency to catalyze this reaction is poor compared to GRXs (Bedhomme et al., 2012). It should be noted, however, that the involvement of GRXs and TRXs in deglutathionylation depends on conditions prevailing in vivo, including expression level of the two types of proteins. GRXs are small proteins with GSH-dependent disulfide oxidoreductase activity present in almost all living organism. GRXs belong to the TRX superfamily and can be categorized in three different classes, depending on the structure of their active site. GRXs have been well studied and reviewed in photosynthetic organisms (Rouhier et al., 2008; Zaffagnini et al., 2012b,c).

Like ROS, RNS such as NO can react with redox sensitive Cys thiols to form nitrosothiols (-SNO) in the process of protein S-nitrosylation (Wilson et al., 2008) (Figure 1). This modification occurs via the direct reaction of a Cys thiolate with RNS molecules, metal-mediated nitrosylation or trans-nitrosylation by $S$-nitrosothiols such as GSNO (Zaffagnini et al., 2016). This latter molecule results from the $S$-nitrosylation of cellular GSH. The mechanism of GSNO formation is not yet fully understood, but likely involves the $S$-nitrosylation of GSH by NO. GSNO is known as an important NO reservoir and donor in plant cells and is also able to induce protein $S$-glutathionylation (Zaffagnini et al., 2016). Furthermore, it is known that $S$-nitrosylated protein thiols can become $S$-glutathionylated by GSH (Mohr et al., 1999). The conditions that lead to $S$-nitrosylation or $S$-glutathionylation by GSNO still remain unclear. The reverse reaction of protein $S$-nitrosylation, denitrosylation, can be favored by reductant such as ASC, DTT and GSH. In vivo denitrosylation is though to be related to TRX and GSNO reductase systems (Benhar et al., 2009).

Protein $S$-sulfhydration is an emerging redox modification promoted by $\mathrm{H}_{2} \mathrm{~S}$ that can modify Cys residues on protein to form persulfide groups (R-SSH) as mentioned above (Figure 1).
The molecular mechanism leading to protein $S$-sulfhydration remains unclear. It was proposed that $\mathrm{H}_{2} \mathrm{~S}$ could react with an oxidized Cys residue or with ROS to form a more reactive intermediate which could react with sensitive thiolate anions (Finkel, 2012; Sen et al., 2012; Couturier et al., 2013). Little is known about the effects of protein $S$-sulfhydration in plants. In animals, S-sulfhydration of glyceraldehyde-3phosphate dehydrogenase (GAPDH) was originally shown to increase its enzyme activity (Mustafa et al., 2009) as opposed to $S$-glutathionylation and $S$-nitrosylation that are known to inactivate the enzyme (Padgett and Whorton, 1995; Cotgreave et al., 2002). However, the effect of $S$-sulfhydration on GAPDH was later revisited and the modification of Cys156 was shown to inhibit enzyme activity (Jarosz et al., 2015). The sensitivity of animal GAPDH activity to different redox modifications nevertheless suggests complex interactions between various redox signals.

\section{EFFECTS OF REDOX MODIFICATIONS OF GLYCOLYTIC, FERMENTATIVE AND RESPIRATORY METABOLISM ENZYMES}

\section{Glycolysis and Fermentation}

Redox regulation of sugar-related metabolic pathways seems to have a fundamental role in photosynthetic organisms. For example, many enzymes from starch metabolism were shown to be redox-sensitive and suggested to be regulated in function of the light/dark dependent redox state of chloroplast (Skryhan et al., 2018). In plants, the glycolytic pathway exists in the cytosol and the plastids (Plaxton, 1996). Many chloroplastic isoforms of glycolytic enzymes take part in the Calvin-Benson pathway, for which redox regulation has been well studied (Michelet et al., 2013). However, less information is available on redox regulation of the cytosolic glycolytic pathway in plants, except for NADdependent GAPDH which has been used as a model for protein redox PTMs (Holtgrefe et al., 2008; Bedhomme et al., 2012; Zaffagnini et al., 2014; Hildebrandt et al., 2015). Several enzymes from the cytosolic glycolytic pathway have been identified in different surveys as potential targets of redox modifications in A. thaliana (Table 1). Nevertheless, few of these identified targets have also been studied to understand the impact of redox modification on their protein function, including enzymatic activity. Here we analyze literature data on cytosolic glycolytic enzymes which activity and functions were shown to be affected by Cys redox modifications (Figure 2).

Cytosolic FBA catalyzes the reversible interconversion of fructose-1,6-bisP to glyceraldehyde $3 \mathrm{P}$ and dihydroxyacetone phosphate. FBA6 from A. thaliana was shown to undergo S-glutathionylation in vitro (van der Linde et al., 2011). Incubation of recombinant FBA6 in the presence of GSSG or GSNO led to FBA6 activity inhibition by $S$-glutathionylation. The presence of fructose-1,6-bisphosphate, protected it from inhibition by both treatments. ESI-MS analysis of FBA6 identified S-glutathionylation of Cys68 after incubation with GSSG. Interestingly, ESI-MS analysis showed S-nitrosylation 
TABLE 1 | List of different redox modifications of $A$. thaliana proteins from glycolysis, fermentation, and TCA cycle identified from literature data.

\begin{tabular}{llll}
\hline $\begin{array}{l}\text { Cytosolic/mitochondrial } \\
\text { enzymes }\end{array}$ & S-glutathionylation & S-nitrosylation & S-sulfhydration \\
modifications or & & \\
unknown
\end{tabular}

\section{GLYCOLYSIS}

\section{Suc synthase}

SUS4 (At3g43190)

SuS1 (At5g20830)

Like protein (At5g20280)

Phosphoglucomutase

PGM3 (At1g23190)

PGM2 (At1g70730)

Glucose 6 phosphate isomerase

PGIC (At5g42740)

Phosphofructokinase

PFP- PFK (At1g20950, At1g76550)

PFP-PFK (At1g12000)

PFK7 (At5g56630)

PFK1 (At4g29220)

PFK3 (At4g26270)

PFK6 (At4g32840)

Fructose-bisphosphate aldolase

FBA8 (At3g52930)

FBA6 (At2g36460)

FBA4 (At5g03690)

FBA5 (At4g26530)

FBA7 (At4g26520)

Triosephosphate isomerase

cTPI (At3g55440)

1

$1 \quad 8$ [Cys $\left.^{349 / 731}\right]$

8 [Cys $\left.{ }^{349 / 731}\right]$

$8+13$

$8+13$

13

8 [Cys $\left.{ }^{28 / 586}\right]$

8 [Cys ${ }^{166}$ ]

$1 \quad 9$

2 [Cys $\left.{ }^{68 / 173}\right]$

2 [Cys $^{173}$ ], 8

8

3, $4\left[\right.$ Cys $\left.^{127 / 218}\right]$

8 [Cys ${ }^{127}$ ], 9, 10

[Cys $^{127 / 218}$ ], 11

[Cys $^{127 / 218}$ ]

Glyceraldehyde phosphate

dehydrogenase

GapC1 (At3g04120)

GapC2 (At1g13440)

Phosphoglycerate kinase

PGK3 (At1g79550)

Phosphoglycerate mutase

PGAM1 (At1g09780)

PGAM like (At5g64460)

Family protein (At5g62840)

Enolase

ENO2 (At2g36530)

Pyruvate kinase

Family protein (At5g56350)

PK (At3g52990; At2g36580;

At5g08570; At3g55650;

At4g26390)

PK (At5g63680)

PEPC

PEPC1 (At1g53310)

PPC2 (At2g42600)

FERMENTATION

Lactate dehydrogenase

LDH (At4g17260)
$8\left[\mathrm{Cys}^{420}\right]$

8 [Cys ${ }^{419}$ ] 13
1, 5 [Cys $^{155}$ ], 6
8 [Cys $^{155}$ ], 9, 12 [Cys ${ }^{155}$ ]
1, 6 [Cys ${ }^{155}$ ]
6 [Cys ${ }^{155 / 159}$ ]
13, 16, 15 [Cys $^{160}$ ]
19, 20
13,14
19,20

9

13

19

8, 10 [Cys $^{100}$ ]

9 [Cys ${ }^{103}$ ]

13

13

13

8 [Cys ${ }^{318}$ ], 9

13,14

8 [Cys $^{113 / 154 / 425}$ ]

13

13

13
19

16

16

16 
TABLE 1 | Continued

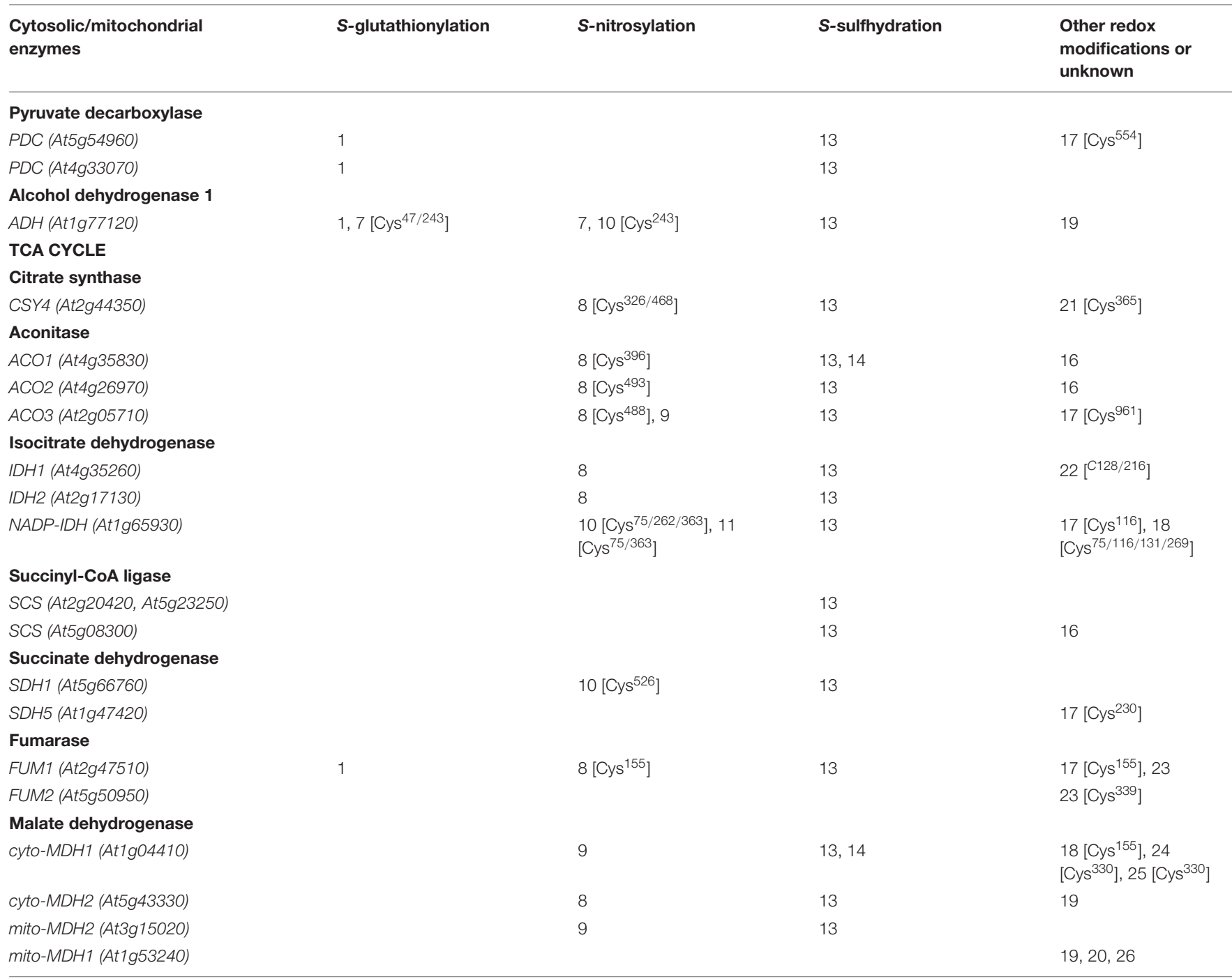

Numbers in columns refer to the publications in the footnotes. When identified, modified residues are indicated between brackets.

1. (Dixon et al., 2005); 2, (van der Linde et al., 2011); 3, (Ito et al., 2003); 4, (Dumont et al., 2016); 5, (Bedhomme et al., 2012); 6, (Holtgrefe et al., 2008); 7, (Dumont et al., 2018); 8, (Hu et al., 2015); 9, (Lindermayr et al., 2005); 10 (Fares et al., 2011); 11, (Puyaubert et al., 2014); 12, (Zaffagnini et al., 2013b); 13, (Aroca et al., 2017a); 14, (Aroca et al., 2015); 15, (Aroca et al., 2017b); 16, (Akter et al., 2015); 17, (Liu et al., 2014); 18, (Alvarez et al., 2009b); 19, (Wang et al., 2012); 20, (Alvarez et al., 2009a); 21, (Schmidtmann et al., 2014); 22, (Yoshida and Hisabori, 2014); 23, (Zubimendi et al., 2018); 24, (Hara et al., 2006); 25, (Huang et al., 2018); 26, (Yoshida and Hisabori, 2016).

and S-glutathionylation of Cys173 after treatment with GSNO, suggesting that the two modifications were induced by GSNO. FBA6 was also shown to co-localize with TRXh in the cytosol and in nucleus using $A$. thaliana protoplasts (van der Linde et al., 2011). However, it is not clear if FBA6 subcellular localization and co-localization with $\mathrm{TRX} h$ is related to redox modification of the enzyme.

Cytosolic triosephosphate isomerase equilibrates the pools of fructose-1,6-bisP and glyceraldehyde 3P and dihydroxyacetone phosphate. S-glutathionylation of cTPI was originally detected in vivo in $A$. thaliana cell cultures treated with BioGEE, a biotinylated analog of GSH (Ito et al., 2003). Recombinant cTPI was shown to be sensitive to inhibition by treatments inducing proteins $S$-glutathionylation such as GSSG and diamide + GSH
(Ito et al., 2003; Dumont et al., 2016). Inactivation of cTPI by $S$-glutathionylation could be reversed enzymatically by cytosolic GRXC1 and GRXC2 (Dumont et al., 2016). Moreover, two Cys residues (Cys127 and Cys218) were identified as potential target of S-glutathionylation. Mutation of Cys127 to Ser caused a large decrease in the enzyme activity while mutation of Cys 218 to Ser had less effect on cTPI activity. Inhibition of the Cys218 mutant by $S$-glutathionylation was similar to the inhibition measured for the wild type cTPI, meaning that redox modification of this residue was not responsible for the loss of cTPI activity. These results suggest that Cys127 is probably the major target of $S$-glutathionylation and is more important for enzyme activity (Dumont et al., 2016). Both Cys127 and Cys218 residues were also found as potential $S$-nitrosylation targets in $A$. thaliana 


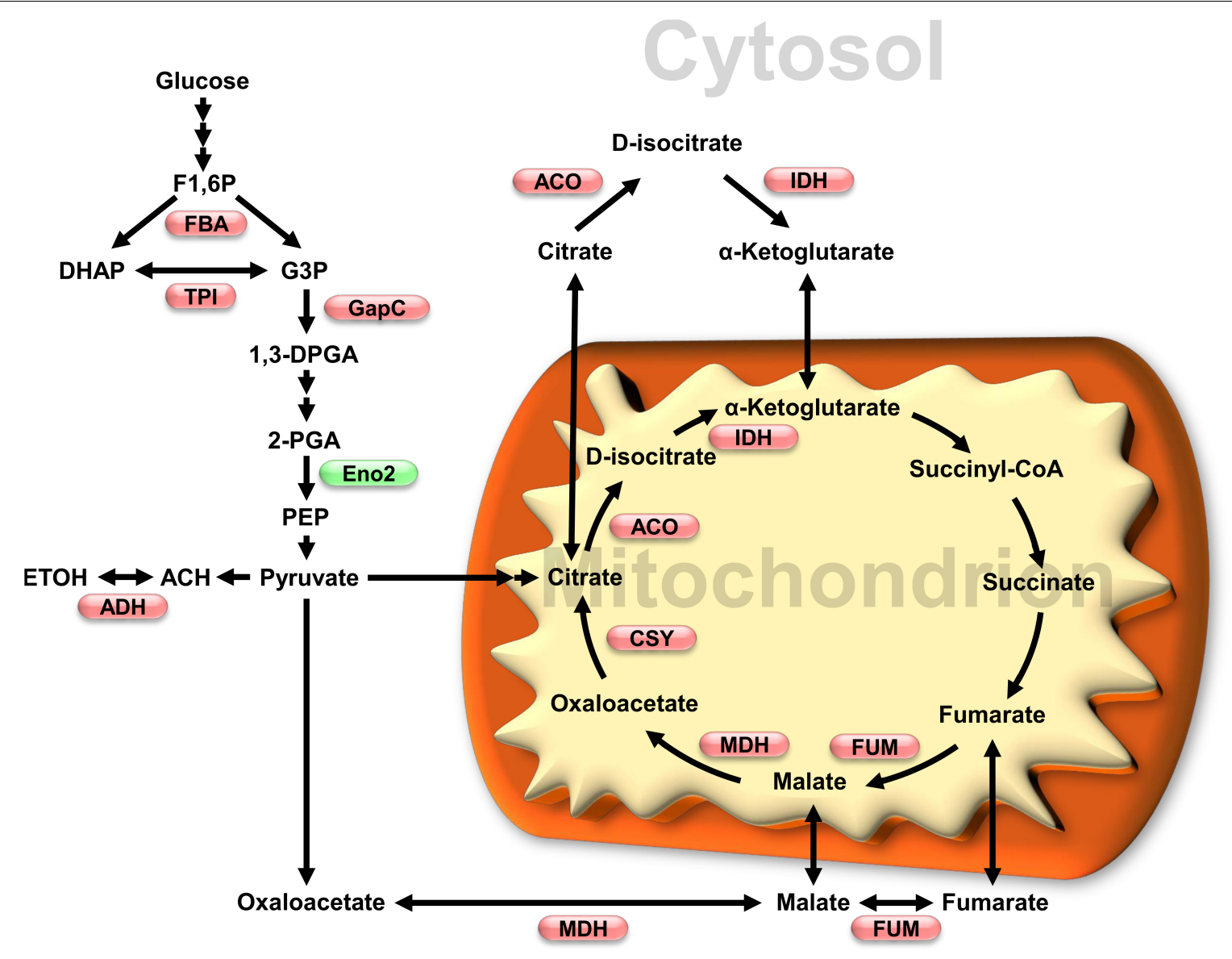

FIGURE 2 | Impact of oxidative stress on glycolytic and TCA cycles enzymes activity. Enzymes which activity has been shown to be affected by redox modification are shown in a metabolic scheme that also includes subcellular localization. Red and green, respectively, indicate inhibition and activation under oxidative conditions. Enzymes and metabolites abbreviations: FBA, fructose-1,6-bisphosphate aldolase; TPI, triosephosphate isomerase; GapC, glyceraldehyde 3-phosphate dehydrogenase; Eno2, enolase 2; ADH, alcohol dehydrogenase; ACO, aconitase; IDH, isocitrate dehydrogenase; MDH, malate dehydrogenase; FUM, fumarase; CSY, citrate synthase. Metabolites: F1,6P, fructose-1,6-bisphosphate; DHAP, dihydroxyacetone phosphate; G3P, glyceraldehyde 3-phosphate; 1,3DPGA, 1,3-bisphosphoglycerate; 2-PGA, 2-phosphoglycerate; PEP, phosphoeno/pyruvate; ACH, acetaldehyde; ETOH, ethanol.

(Fares et al., 2011; Hu et al., 2015). cTPI was also found as a putative target of other redox modifications (Table 1). It is reasonable to hypothesize that $S$-glutathionylation of cTPI occurring in vivo would result in metabolic effects similar to those found in CTPI antisense roots, where a decrease in cTPI was shown to result in a partial redirection of the glycolytic flux to the PPP (Dorion et al., 2012; Valancin et al., 2013).

NAD-dependent GAPDH catalyzes the oxidation and phosphorylation of glyceraldehyde $3 \mathrm{P}$ in the cytosol to produce 1,3-bisphosphoglycerate and NADH. This enzyme is well known to undergo several redox PTMs and to display moonlighting functions in plant cells (Zaffagnini et al., 2014; Hildebrandt et al., 2015). For these reasons, cytosolic NAD-dependent GAPDH (GapC) is considered as a redox sensor in plant cells (Morigasaki et al., 2008; Hildebrandt et al., 2015; Schneider et al., 2018). The two cytosolic isoforms of GapC (GapC1 and GapC2) undergo S-glutathionylation in vivo after incubation of A. thaliana cell cultures with biotinylated GSSG (BioGSSG) (Dixon et al., 2005). Recombinant A. thaliana GapC1 and
GapC2 showed a decrease in their activity after incubation with GSNO, $\mathrm{H}_{2} \mathrm{O}_{2}, \mathrm{GSH}+\mathrm{H}_{2} \mathrm{O}_{2}$ and GSSG (Holtgrefe et al., 2008; Bedhomme et al., 2012). After treatment with $\mathrm{GSH}+\mathrm{H}_{2} \mathrm{O}_{2}$ or GSSG, GapC1 activity could be recovered by addition of DTT, however, inhibition caused by $\mathrm{H}_{2} \mathrm{O}_{2}$ alone led to an irreversible modification (Bedhomme et al., 2012). Site directed mutagenesis demonstrated that Cys155 is essential for GapC1 activity while mutation of Cys159 did not affect enzyme activity. While both Cys residues are involved in substrate binding, only the highly acidic Cys155 along with His181 have catalytic functions in the active site (Zaffagnini et al., 2013a). Deglutathionylation of GapC1 could be performed in vitro by different isoforms of TRXs as well as GRXC1, the latter being significantly more efficient (Bedhomme et al., 2012). Recombinant GapC1 was also shown to undergo S-nitrosylation on Cys155, leading to inhibition of the enzyme (Zaffagnini et al., 2013b). Inhibition was reversible with addition of GSH or DTT. However, TRXs were ineffective for recovering GapC1 activity from the nitrosylated enzyme. Redox-dependent inhibition of GapC1 and GapC2 
activities would have direct consequences on plant primary metabolism. Indeed, A. thaliana double KO mutants for both GapC isoforms showed reduced levels of ATP, downstream glycolytic intermediates and organic acids from the TCA cycle (Guo et al., 2014). These results suggest a lower glycolytic flux to pyruvate due to the lack of GapCs. The double KO mutants also had a higher NADPH/NADP ratio. It is thus possible that low GapCs activity could increase carbon flux through PPP similarly to what was proposed for low cTPI (Dorion et al., 2012; Valancin et al., 2013; Guo et al., 2014). KO lines showed lower oil accumulation in seeds probably due to the reduction in precursors and energy required for fatty acid synthesis, thus altering lipid metabolism (Guo et al., 2014).

The GapC1 isoform, has been shown to accumulate in the cell nucleus during abiotic or biotic stresses (Vescovi et al., 2013; Henry et al., 2015; Testard et al., 2016) suggesting a moonlighting function in response to oxidative stress. Cd stress was shown to increase NO in A. thaliana root tips. Accumulation of GapC1 in cell nucleus was demonstrated after $\mathrm{Cd}$ treatment and also after treatment with L-BSO, an inhibitor of GSH biosynthesis which is known to induce oxidative stress in plants (Vescovi et al., 2013). Interestingly, mutation of Cys155 to Ser did not prevent GapC1 accumulation in the nucleus, suggesting that redox modification of this Cys during $\mathrm{Cd}$ stress is not required for its translocation to the nucleus (Vescovi et al., 2013). Accumulation of GapC in cell nucleus was also shown following stress induced by $\mathrm{H}_{2} \mathrm{O}_{2}$ or GSNO in A. thaliana protoplasts (Schneider et al., 2018). In this case, mutation of both Cys156 and Cys160 prevented an increase of GapC localization in cell nucleus following oxidative stress treatments. These results suggest that redox modification of GapC Cys residues is necessary for its higher nucleus accumulation under stress caused by $\mathrm{H}_{2} \mathrm{O}_{2}$ or GSNO (Schneider et al., 2018). The difference in localization following stress with the previous study (Vescovi et al., 2013) could be related to the identity of the stressing agent. Accumulation of GapC in the nucleus was also observed in tobacco BY-2 cells treated with DHS (Testard et al., 2016). DHS is known to trigger an apoptotic-like response in tobacco, and in parallel, to increase ROS and RNS production (Lachaud et al., 2010, 2011; Da Silva et al., 2011). GapC1 accumulation in the nucleus was found to be dependent on NO levels in tobacco cells. Indeed, addition of the NO scavenger [2-(4-carboxyphenyl)-4,4,5,5-tetramethylimidazoline1-oxyl 3-oxide] (cPTIO) prevented accumulation of GapC1 in the nucleus in DHS-treated tobacco cells while addition of a NO donor showed increase in nuclear localization (Testard et al., 2016). A biotin-switch assay also demonstrated that the GapC enzyme present in the nucleus was $S$-nitrosylated. Expression of GapC1 and GapC2 carrying a double mutation for Cys155 and Cys159 in tobacco showed localization to the nucleus (Testard et al., 2016). This supports previous results obtained in Cd stressed A. thaliana root tips in which the redox modification of GapC1 and GapC2 is not a prerequisite to the migration of these enzymes to the nucleus (Vescovi et al., 2013). These data suggest a different mechanism, as proposed in animals, where $S$-nitrosylation of GAPDH promotes binding with Siah1 followed by translocation of the Siah1NO-GAPDH complex into the nucleus (Hara et al., 2005).
Interestingly, GapC1 and GapC2 were both able to bind nucleic acids in tobacco while their mutated forms were not (Testard et al., 2016). GapC1 and GapC2 were also identified as putative targets of S-sulfhydration in A. thaliana (Aroca et al., 2015, 2017a). LC-MS/MS analysis showed modification of Cys159 by $S$-sulfhydration and treatment with NaHS of A. thaliana plants was proposed to increase localization of GapC in the nucleus (Aroca et al., 2017b). GapC was also demonstrated to interact with the plasma membrane-associated $\operatorname{PLD} \delta$ under oxidizing conditions. Indeed, $\mathrm{H}_{2} \mathrm{O}_{2}$ was shown to promote binding of GapC1 and GapC2 to PLD $\delta$. Interaction between GapC and PLD $\delta$ was proposed to increase phosphatidic acid by PLD $\delta$, which could stimulate ROS production via NADPH oxidase. Interaction of oxidized GapC with PLD $\delta$ was shown to play important functions for growth inhibition response to drought stress (Guo et al., 2012).

Enolase converts 2-phosphoglycerate to phosphoenolpyruvate (PEP), the immediate precursor of pyruvate in the glycolytic pathway and a branch point to the shikimic acid pathway. Three ENO genes are present in Arabidopsis. ENO1 encodes a weakly expressed plastidic isoform, while ENO2 and ENO3 encode cytosolic isoforms (Troncoso-Ponce et al., 2018). ENO2 is the only active cytosolic ENO isoform (Andriotis et al., 2010). It was detected as a putative target of several redox modifications (Table 1). ENO2 is thought to be the main ENO isoform operating in most plant cells. Little is known about the effect of these modifications on the enzyme activity, however, addition of diamide in A. thaliana and ice plant cell extracts was reported to increase ENO activity (Anderson et al., 1998). Diamide is a thiol-specific oxidant that promotes protein $S$-glutathionylation in vivo and in vitro (Michelet et al., 2008; Dumont et al., 2016). The authors suggested that the increase in ENO activity could be caused by a disulfide bond between Cys 318 and Cys346.

Alcohol dehydrogenase catalyzes the reduction of acetaldehyde to ethanol and is the final step of the ethanolic fermentation pathway. It is encoded by a single gene in A. thaliana (Strommer, 2011) and is essential for survival in hypoxia (Ismond et al., 2003). Recently, we showed that ADH activity inhibition by $\mathrm{H}_{2} \mathrm{O}_{2}$ treatment in A. thaliana cell cultures while oxidative treatment with diamide did not affect the enzyme activity. This suggests an $\mathrm{H}_{2} \mathrm{O}_{2}$-mediated redox modification of this enzyme. While in vitro $S$-glutathionylation of the recombinant enzyme led to the identification of Cys47 and Cys243 as redox sensitive thiols, it did not affect the ADH activity. $\mathrm{ADH}$ was, however, sensitive to irreversible inhibition in vitro by $\mathrm{H}_{2} \mathrm{O}_{2}$ and reversible inhibition by the NO donor, diethylamine NONOate. Since $\mathrm{NAD}^{+}$or NADH prevented this inhibition at concentrations compatible with those occurring in plant cells, it was hypothesized that nicotinamide adenine dinucleotides could mediate ADH protection in vivo (Dumont et al., 2018).

\section{TCA Cycle and Glyoxylate Cycle}

Many TCA cycle enzymes were shown to respond to oxidative stress in plants. Treatment of $A$. thaliana cell cultures with $\mathrm{H}_{2} \mathrm{O}_{2}$ caused the reduction in protein abundance for ACO, the E2 subunit of the pyruvate dehydrogenase complex, 2-oxoglutarate dehydrogenase, FUM, and succinyl CoA ligase (Sweetlove 
et al., 2002). ACO, IDH, FUM, and MDH were reported as $S$-glutathionylation targets in $C$. reinhardtii (Zaffagnini et al., 2012a). Several proteomic surveys also reported redox modifications of TCA cycle enzymes in A. thaliana (Table 1). In spite of these studies, little information is yet available on the possible molecular mechanisms involved in the redox regulation of these enzymes.

Mitochondrial citrate synthase catalyzes the first enzymatic reaction of the TCA cycle by condensing acetyl-CoA and oxaloacetate to form citrate. A. thaliana also possesses peroxisome-localized citrate synthase isoforms, which take part in the glyoxylate cycle and fatty acid respiration (Pracharoenwattana et al., 2005). Addition of diamide in crude extract from pummelo fruit, Solanum tuberosum and A. thaliana decreased citrate synthase activity. Addition of DTT caused an increase in citrate synthase activity in pummelo fruit and S. tuberosum crude extracts, however, no significant changes were observed in A. thaliana (Stevens et al., 1997). The main mitochondrial citrate synthase isoform (CS4) was shown to be inhibited by $\mathrm{H}_{2} \mathrm{O}_{2}$ (Schmidtmann et al., 2014). The enzyme was also shown to form an aggregate in a redox-dependent manner. Addition of E. coli TRX (with NADPH-TRX reductase) resulted in an increase the activity of the enzyme previously purified under non-reducing condition. Interestingly, site directed mutagenesis showed that mutation of Cys365 to Ser reduced the sensitivity of citrate synthase to oxidation and also reduced activation by TRX (Schmidtmann et al., 2014). This Cys residue was also found $S$-nitrosylated in the same isoform of citrate synthase (Hu et al., 2015).

Aconitase catalyzes the reversible isomerisation of citrate to isocitrate in the TCA cycle. ACO is an iron-sulfur containing protein with isoforms localized in mitochondria and cytosol. In the latter case, it participates to the glyoxylate cycle (Eprintsev et al., 2015). ACO was shown to be inactivated by $\mathrm{H}_{2} \mathrm{O}_{2}$ in S. tuberosum (Verniquet et al., 1991) and by both $\mathrm{H}_{2} \mathrm{O}_{2}$ and $\mathrm{NO}$ in tobacco leaves (Navarre et al., 2000). Following these results, it was proposed that ACO inhibition by ROS or RNS could take part in plant pathogen response. Indeed, redoxdependent inhibition of ACO is suggested to lead to elevated levels of citrate (Navarre et al., 2000; Gupta et al., 2012), which could in turn induce alternative oxidase (Vanlerberghe and Mclntosh, 1996). This process is known to be implicated in resistance to Tobacco Mosaic Virus and other viruses (Chivasa and Carr, 1998; Murphy et al., 1999; Navarre et al., 2000). Induction of alternative oxidase via citrate accumulation due to ACO $S$-nitrosylation during hypoxia was also proposed as a response mechanism to control ROS production in mitochondria during stress conditions (Gupta et al., 2012). Accumulation of citrate due to ACO inhibition during hypoxia was also proposed to cause a metabolic shift toward amino acid biosynthesis as an adaptation strategy (Gupta et al., 2012). Resistance to paraquat treatment was enhanced in ACO-silenced tobacco or A. thaliana KO lines, suggesting that inhibition of ACO activity during oxidative stress would help plant to cope with oxidative stress (Moeder et al., 2007). Cytosolic ACO was also found to be related to cell death. This case, it was suggested that $\mathrm{Fe}^{2+}$ released by the oxidized enzyme could react with
$\mathrm{H}_{2} \mathrm{O}_{2}$ to form hydroxyl radicals that would enhance cell death (Moeder et al., 2007).

Mitochondrial $\mathrm{NAD}^{+}$-dependent IDH $(\mathrm{mIDH})$ catalyzes the oxidative decarboxylation of isocitrate and forms 2-oxoglutarate, $\mathrm{CO}_{2}$ and $\mathrm{NADH}$. In yeast, IDH is a heterodimer composed of two subunits called IDH-r (regulatory) and IDH-c (catalytic). Yeast IDH is activated by AMP and is inactivated by formation of intermolecular disulfide bonds located on IDH-c subunits (Taylor et al., 2008; Garcia et al., 2009; Yoshida and Hisabori, 2014). In A. thaliana, $\mathrm{mIDH}$ has a heterodimeric structure formed by IDH-c and IDH-r that is insensitive to adenylates (Yoshida and Hisabori, 2014). Each of these subunits type alone has been shown to be inactive. It was demonstrated that treatment with $50 \mu \mathrm{M}$ $\mathrm{CuCl}_{2}$ induced oxidation of mIDH-r subunit but not mIDH-c. Oxidative inactivation of the enzyme activity could be partially reversed by DTT. Non-reducing SDS-PAGE analysis showed the formation of IDH-r trimers following oxidation of the protein. Oxidized IDH-r trimers could be reduced back to monomers on non-reducing gels with high concentrations of DTT. Lower DTT concentrations were needed to reduce oxidized IDH-r in presence of the mitochondrial TRXo1 (Yoshida and Hisabori, 2014), suggesting redox regulation of this enzyme by TRXs as proposed before (Yoshida et al., 2013). Mass spectrometry analysis identified that Cys128 and Cys216 were involved in the formation of disulfide bonds in IDH-r.

Cytosolic NADPH-IDH activity measured from A. thaliana leaves and roots using the assumption that the cytosolic isoform corresponds to $90 \%$ of the total activity (Galvez and Gadal, 1995; Chen, 1998). Extracts were treated with $\mathrm{H}_{2} \mathrm{O}_{2}, 3$ morpholinosydnonimine (SIN-1, a NO donor) and GSNO. $\mathrm{H}_{2} \mathrm{O}_{2}$ decreased NADPH-IDH activity in roots but not in leaves. Both SIN-1 and GSNO had inhibitory effects on IDH activity in roots and leaves. Interestingly, addition of GSH in leaves extracts also decreased IDH activity (Leterrier et al., 2012).

Fumarase catalyzes the reversible conversion of fumarate to Lmalate. A. thaliana possesses two genes for FUM isoforms. FUM1 is localized in mitochondria where it plays an essential role in TCA cycle. FUM2 is cytosolic and is required for accumulation of fumarate during the day (Pracharoenwattana et al., 2010). Accumulation of fumaric acid due to cytosolic FUM2 activity was shown to be essential for cold adaptation in A. thaliana (Dyson et al., 2016). Diamide treatment was recently shown to decrease the fumarate hydratase and L-malate hydratase activity of both recombinant FUM1 and FUM2 from $A$. thaliana (Zubimendi et al., 2018). Addition of DTT allowed the two isoforms to recover their enzymatic activity. Diamide treatment also induced the formation of high molecular weight aggregates. These aggregates could be reduced by incubation with $A$. thaliana leaf extracts supplemented with NADPH, suggesting reduction of aggregates via a TRX and NADPH-dependent TRX reductase mechanism. LC-MS/MS analysis also demonstrated the occurrence of a Cys339-Cys339 disulfide bond on FUM2.

NAD-dependent Malate dehydrogenase (NAD-MDH) catalyzes the reversible oxidation of malate to oxaloacetate while using $\mathrm{NAD}^{+}$to form NADH. NAD-MDH isoforms are localized in the cytosol, mitochondria, peroxisomes, and chloroplasts. Chloroplastic NADP-dependent $\mathrm{MDH}$ has been shown to 
be redox regulated via disulfide bonds by the chloroplastic ferredoxin-TRX system on both its $\mathrm{N}$ - and C-terminal extensions (MiginiacMaslow et al., 1997; Carr et al., 1999; Lemaire et al., 2005). NAD-MDHs do not have these redox regulated extensions in their sequences. Nevertheless, mitochondrial $\mathrm{MDH}(\mathrm{mMDH})$ was shown to form disulfide bonds upon oxidative treatment with $50 \mu \mathrm{M} \mathrm{CuCl}_{2}$ (Yoshida and Hisabori, 2016). However, kinetics parameters of oxidized $\mathrm{mMDH}$ were not significantly affected compared to the reduced form. Moreover, mitochondrial TRXo1 was not able to reduce oxidized mMDH. It was then suggested that $\mathrm{mMDH}$ is probably not a redox-regulated enzyme, and that variations of the ATP/ADP ratio were a more effective mechanism for regulation of the enzyme activity (Yoshida and Hisabori, 2016).

While mMDH principal function is to participate in the TCA cycle, cytosolic MDH (cMDH) participates in the malate valve that allows transfer of reducing equivalents between subcellular compartments (Scheibe, 2004). Recombinant $\mathrm{cMDH}$ could be oxidized using $50 \mu \mathrm{M} \mathrm{CuCl} 2$ while forming intermolecular disulfide bond in the dimer structure (Hara et al., 2006). Oxidized cMDH could be reduced and reactivated by DTT and TRXh1. Site-directed mutagenesis showed that mutation of Cys330 to Ser prevented the enzyme from being inactivated by $\mathrm{CuCl}_{2}$ and from forming intermolecular disulfide bonds while other mutants behaved similarly as the wild type (Hara et al., 2006). Recently, recombinant $\mathrm{cMDH}$ from $A$. thaliana was shown to be inhibited by $\mathrm{H}_{2} \mathrm{O}_{2}$. Following this treatment, cMDH could be reactivated by five different cytosolic TRX isoforms (TRXh15) (Huang et al., 2018). The inhibitive effect of $\mathrm{H}_{2} \mathrm{O}_{2}$ on $\mathrm{MDH}$ activity in purified cytosolic fractions was not observed with $\mathrm{MDH}$ from purified mitochondrial fractions, consistently with previous results (Yoshida and Hisabori, 2016). In vivo $\mathrm{MDH}$ activity was reduced in mutant plants deficient in the activity of the $\mathrm{H}_{2} \mathrm{O}_{2}$ scavenging enzyme catalase (cat2) and in TRX reductase deficient double mutants ( $n$ tra/ntrb), which display lower TRXh activity (Huang et al., 2018). This work also confirmed the presence of a Cys330-Cys330 intramolecular disulfide bond in the oxidized protein structure. Cys79 was found to be overoxidized to sulfenic acid. However, this modification did not seem to affect cMDH activity. The authors proposed a redox mechanism where Cys330 of one subunit makes a disulfide bond with the Cys330 from another dimer leading to an unstable tetramer. In this context, the original dimer structure would dissociate, leading to newly formed dimers linked by a Cys330-Cys330 disulfide bond (Huang et al., 2018). Interestingly, literature data have shown that overexpression of $\mathrm{MDH}$ in different plant organisms lead to a higher tolerance to different stress via an increase in malate synthesis (Tesfaye et al., 2001; Chen et al., 2015; Wang et al., 2016).

\section{Possible Indirect Impact of Oxidative Stress Through Effects on Enzyme Regulatory Phosphorylation}

Protein redox modifications discussed above are a direct consequence of oxidative stress on protein properties. However, oxidative stress can also impact enzyme properties indirectly.
For example, $S$-glutathionylation of TRXf in chloroplast could alter its oxido-reductase activity toward targets, affecting them indirectly (Michelet et al., 2005). The SnRK1 is an essential regulator of plant metabolism by direct phosphorylation of a number of enzymes involved in carbohydrate metabolism and nitrogen assimilation (Piattoni et al., 2017; Wurzinger et al., 2018). Recently, it was determined that $A$. thaliana SnRK1 kinase activity is sensitive to inhibition by $\mathrm{H}_{2} \mathrm{O}_{2}$. Mutation of Cys200 prevented inhibition of the SnRK1 kinase activity, suggesting this residue as a target site for redox modification (Wurzinger et al., 2017). These results suggest that redox regulation of SnRK1 could then indirectly affect its phosphorylation targets.

Another impact of oxidative stress on protein phosphorylation could involve oxidation of methionine residues to methionine sulfoxide. Phosphorylation of nitrate reductase Ser534 in A. thaliana was shown to be dependent on the redox state of Met538. The oxidized form of this residue prevented enzyme phosphorylation (Hardin et al., 2009). These results suggest that oxidative stress can not only induce redox modification in enzymes structure but can also indirectly interfere with other types of modifications such as phosphorylation. A cross-species survey suggests that nitrate reductase is probably not a unique occurrence for this proposed mode of regulation in plants (Rao et al., 2013).

\section{FORMATION OF PROTEIN COMPLEXES}

Besides the direct modification of metabolic enzymes, the formation of metabolic complexes has also been suggested as a way to control carbon flux in plant cells. It was first found that glycolytic enzymes were able to associate at the outer surface of mitochondria in A. thaliana. LC-MS/MS analysis showed the presence of hexokinase, FBA, cTPI, GapC1 and GapC2, phosphoglycerate mutase, ENO and pyruvate kinase in purified mitochondrial fractions. Moreover, the activity of all glycolytic enzymes was detected in purified mitochondria. Additional evidence came from the use of YFP-fusion proteins to show colocalization of FBA and ENO with mitochondria (Giegé et al., 2003). Later, association of glycolytic enzyme with mitochondria was shown to be dependent on respiration rate in $A$. thaliana and S. tuberosum. Indeed, stimulation of respiration increased glycolytic enzymes activity associated with purified mitochondria samples while inhibition of respiration had the opposite effect. Addition of nitrite to stimulate carbon flux through the PPP also increased association of glycolytic enzymes with mitochondria (Graham et al., 2007). This latter experiment suggests that during conditions where NADPH is required, (e.g., for nitrite assimilation or during oxidative stress), association of glycolytic enzymes with mitochondria could be stimulated in order to favor the PPP. There is also evidence of substrate channeling implying the presence of a functional glycolytic metabolon associated with mitochondria (Graham et al., 2007). Pull-down experiments suggested interaction of FBA with GapC but also with a VDAC located in the outer membrane of the mitochondria. These latter results suggest a mechanism where glycolytic enzyme could form a 
metabolon anchored at the outer membrane of mitochondria (Graham et al., 2007). FBA6 and GapC were initially found to preferentially interact with VDAC3 by far western blotting under oxidizing conditions in vitro, while addition of DTT prevented the interaction (Wojtera-Kwiczor et al., 2013). This study also showed interaction of FBA6 and GapC with actin under oxidizing conditions, supporting an earlier report in which FBA was proposed to interact with cellular structures (van der Linde et al., 2011). Interaction of FBA with actin has also been shown to decrease its activity (Garagounis et al., 2017). Recently, the conditions under which glycolytic enzymes bind to the mitochondria were revisited in A. thaliana. Colocalization of GapC with mitochondria was shown to be increased under reducing conditions compared to oxidative conditions (Schneider et al., 2018). The authors also used VDAC3 incorporated into a lipid bilayer to show an increase in binding properties with GapC under reducing conditions. These results differed from those previously obtained by far western blotting and could it be rationalized that the latter method does not represent native conditions for protein interaction. The authors proposed a mechanism in which glycolytic enzymes would be associated with mitochondria under normal conditions to provide pyruvate for respiration. Under stress, oxidized GapC would be relocated to the nucleus where it would serve to enhance defense-response genes. This mechanism would also lead to increased flux through PPPs producing NADPH as reducing power. Plant-specific non-phosphorylating GAPDH (GapN) was also proposed as an alternative to produce NADPH by the glycolytic pathway under oxidative stress condition (Schneider et al., 2018).

Formation of large protein complexes such as glycolytic enzymes anchored at the outer membrane of mitochondria appears to occur during stress and could be playing essential functions. A well accepted explanation for the formation of these complexes is to reduce the availability of intermediates in competing pathways. Metabolite channeling could help redirect the carbon flux through PPP while reducing some biosynthetic pathways. However, the impact of these complexes on metabolites and $\mathrm{C}$ flux regulation remains unclear and further work will be needed to elucidate the importance of this mechanism in response to oxidative conditions.

\section{CHANGES IN METABOLITE POOLS AND METABOLIC FLUXES}

Changes in cellular metabolites during A. thaliana response to oxidative stress induced by non-lethal menadione treatment of cell cultures has revealed an adaptative strategy based on the modulation of carbon fluxes through primary metabolism. Menadione is a redox-active quinone that provokes oxidative stress though the production of superoxide (Sweetlove et al., 2002). Menadione treatment was shown to increase the abundance of 6-phosphogluconate and ribose-5-phosphate suggesting a redirection of carbon flux through PPP (Baxter et al., 2007). These changes were highly dynamic as the abundance of these metabolites increased in the first hours of the treatment and then returned to the control levels. A rapid accumulation of 3PGA was also consistent with inhibition of downstream fluxes. Accordingly, malate abundance decreased in these conditions. Kinetic analysis of ${ }^{13} \mathrm{C}$-labeled compounds following labeling with ${ }^{13} \mathrm{C}$-Glc suggested a reduction of $\mathrm{C}$ flux through the TCA cycle because of decreased labeling for citrate, isocitrate, 2oxoglutarate, succinate, fumarate and malate. The metabolomic response of $A$. thaliana to oxidative stress was further studied using roots similarly treated with menadione (Lehmann et al., 2009, 2012). As previously observed, a rapid decrease of TCA cycle metabolites and an increase in PPP intermediates such as ribose 5-P and ribulose 5-P was measured after the occurrence of stress (Lehmann et al., 2009, 2012). Citrate abundance decreased at $0.5 \mathrm{~h}$ after menadione treatment but increased after $2 \mathrm{~h}$ compared to the control. In these conditions, ACO activity was also shown to be inhibited (Lehmann et al., 2012). ACO inhibition, as well as accumulation of citrate was also observed in A. thaliana seedlings during oxidative stress (Obata et al., 2011). As mentioned above, high citrate levels have been proposed as a response mechanism to control ROS concentrations in plant cells (Gupta et al., 2012). In contrast to results obtained in cell culture, root treated with menadione showed a decrease in levels of glucose-6-phosphate and fructose-6-phosphate. Similar results showing a decrease in glucose-6-phosphate, fructose6-phosphate fumarate and malate was observed in seedlings exposed to menadione (Obata et al., 2011). In roots, pyruvate and pyruvate-derived amino acids were shown to accumulate under oxidative conditions (Lehmann et al., 2009, 2012). A 5fold increase in pyruvate as well as an increase in citrate levels was also observed in stressed seedlings (Obata et al., 2011). This build-up of pyruvate probably reflects the impact of TCA cycle inhibition on the lower part of glycolysis. It was also shown that metabolites from glycolysis could recover much faster from oxidative stress than metabolites from TCA cycle. The authors suggested that glycolytic enzyme inhibition was limited while inhibition of TCA cycle enzymes such as ACO was stronger and irreversible (Lehmann et al., 2012). Interestingly, addition of DTT to $A$. thaliana leaves, caused opposite metabolic effect to observations made during oxidative stress. In this case, metabolites in the first part of the TCA cycle (aconitate, isocitrate, 2-oxoglutarate) increased as well as succinate, fumarate and malate (Kolbe et al., 2006). Pyruvate levels in DTT-treated tissues were also shown to decrease in contrast to observations made on menadione-stressed roots. Taken together, these results suggest a tight redox regulation on carbon flux through glycolysis and TCA cycle.

Overexpression of the cell death suppression factor, BI-1, is known to induce tolerance to different stresses (Kawai-Yamada et al., 2004). In rice, overexpression of BI-1 was shown to act by enhancing tolerance of cell culture to cell death induced by oxidative stress (Ishikawa et al., 2009, 2013). The authors used overexpression of BI-1 to better understand how plants cope with oxidative stress. During the first hours of menadione treatment, a peak of $\mathrm{H}_{2} \mathrm{O}_{2}$ production was observed in cell cultures. As previously observed in A. thaliana, the authors found that menadione treatment in rice led to an increase in PPP intermediates and in pyruvate while most metabolites from the 
TCA cycle were decreased. Several differences in metabolites were found between BI-1 overexpressors and control cells after $24 \mathrm{~h}$ of stress, including higher concentrations of GSH and GSSG, sugar phosphates, NADH, NADPH and nucleoside triphosphates. The difference was particularly remarkable for NADPH, which was seven times higher in overexpressors as compared to the control cells. These results support the hypothesis that oxidative stress leads to a metabolic shift allowing more production of NADPH thus enhancing plant tolerance to stress. The importance of NADPH generating dehydrogenases in plant adaptation to nitrooxidative stresses has been previously emphasized (Corpas and Barroso, 2014). Not only does NADPH participate in the support of biosynthetic pathways, but it is also as mentioned above, a key player in the cellular detoxification of ROS due to its role as reductant in the ASC/GSH cycle (Noctor et al., 2017).

Studies on photo-oxidative stress and exposure to UV-B which are known to induce oxidative stress has shown common metabolic responses with observations made on menadionetreated cells (Kusano et al., 2011). These results suggest that different stresses probably have an early-response consisting of oxidative regulation of primary carbon metabolism. Indeed, several biotic and abiotic stresses are known to cause an increase in ROS concentrations (Apel and Hirt, 2004).

\section{SUMMARY}

In conclusion, post-translational redox modifications of enzymes from glycolysis and the TCA cycle could play critical roles during the early response of plants to oxidative stress. Inhibition of FBA, cTPI and GapC (Figure 2) would favor carbon flux through PPP in order to produce NADPH necessary to cope with an

\section{REFERENCES}

AbdElgawad, H., Zinta, G., Hegab, M. M., Pandey, R., Asard, H., and Abuelsoud, W. (2016). High salinity induces different oxidative stress and antioxidant responses in maize seedlings organs. Front. Plant Sci. 7:276. doi: 10.3389/fpls. 2016.00276

Airaki, M., Leterrier, M., Mateos, R. M., Valderrama, R., Chaki, M., Barroso, J. B., et al. (2012). Metabolism of reactive oxygen species and reactive nitrogen species in pepper (Capsicum annuum L.) plants under low temperature stress. Plant Cell Environ. 35, 281-295. doi: 10.1111/j.1365-3040.2011. 02310.x

Akter, S., Huang, J., Bodra, N., De Smet, B., Wahni, K., Rombaut, D., et al. (2015). DYn-2 based identification of Arabidopsis sulfenomes. Mol. Cell. Proteom. 14, 1183-1200. doi: 10.1074/mcp.M114.046896

Alscher, R. G., Erturk, N., and Heath, L. S. (2002). Role of superoxide dismutases (SODs) in controlling oxidative stress in plants. J. Exp. Bot. 53, 1331-1341. doi: $10.1093 /$ jexbot $/ 53.372 .1331$

Alvarez, S., Wilson, G. H., and Chen, S. X. (2009a). Determination of in vivo disulfide-bonded proteins in Arabidopsis. J. Chromatogr. B Anal. Technol. Biomed. Life Sci. 877, 101-104. doi: 10.1016/j.jchromb.2008. 11.027

Alvarez, S., Zhu, M. M., and Chen, S. X. (2009b). Proteomics of Arabidopsis redox proteins in response to methyl jasmonate. J. Proteom. 73, 30-40. doi: 10.1016/j. jprot.2009.07.005

Anderson, L. E., Li, A. D., and Stevens, F. J. (1998). The enolases of ice plant and Arabidopsis contain a potential disulphide and are redox sensitive. Phytochemistry 47, 707-713. doi: 10.1016/S0031-9422(97) 00659-6 increase in ROS levels. In support of this, flux measurements and metabolic modeling made using transgenic roots with low cTPI activity (mimicking the effects of $S$-glutathionylation of the enzyme) showed increased flux through the PPP (Dorion et al., 2012; Valancin et al., 2013). Low cTPI and GAPDH activity has also been correlated with higher resistance to oxidative stress as well as increased flux through PPP in non-plant systems (e.g., S. cerevisiae and C. elegans) (Ralser et al., 2007).

Available data from multiple studies indicate that the TCA cycle is deeply affected by oxidative stress. The primary cause seems to be an inhibition of several TCA cycle enzymes (Figure 2), leading to perturbation in $\mathrm{C}$ flux. Redox dependent inhibition of TCA cycle enzymes such as ACO seems to cause an increase in citrate concentrations Accumulation of citrate is thought to play several roles during stress including induction of alternative oxidase to reduce ROS production. Inhibition of the TCA cycle could be beneficial during stress by reducing ROS production due to respiration.

\section{AUTHOR CONTRIBUTIONS}

SD drafted the article and produced the artwork. JR revised the manuscript. JR and SD both approved the final version of the manuscript.

\section{FUNDING}

This work was supported by a Discovery Grant from the National Science and Engineering Research Council of Canada to JR (Grant No. RGPIN 227271).

Andriotis, V. M., Kruger, N. J., Pike, M. J., and Smith, A. M. (2010). Plastidial glycolysis in developing Arabidopsis embryos. New Phytol. 185, 649-662. doi: 10.1111/j.1469-8137.2009.03113.x

Apel, K., and Hirt, H. (2004). Reactive oxygen species: metabolism, oxidative stress, and signal transduction. Annu. Rev. Plant Biol. 55, 373-399. doi: 10.1146/ annurev.arplant.55.031903.141701

Aroca, A., Benito, J. M., Gotor, C., and Romero, L. C. (2017a). Persulfidation proteome reveals the regulation of protein function by hydrogen sulfide in diverse biological processes in Arabidopsis. J. Exp. Bot. 68, 4915-4927. doi: 10.1093/jxb/erx294

Aroca, A., Schneider, M., Scheibe, R., Gotor, C., and Romero, L. C. (2017b). Hydrogen sulfide regulates the cytosolic/nuclear partitioning of glyceraldehyde3-phosphate dehydrogenase by enhancing its nuclear localization. Plant Cell Physiol. 58, 983-992. doi: 10.1093/pcp/pcx056

Aroca, A., Serna, A., Gotor, C., and Romero, L. C. (2015). S-sulfhydration: a cysteine posttranslational modification in plant systems. Plant Physiol. 168, 334-586. doi: 10.1104/pp.15.00009

Bailey-Serres, J., and Voesenek, L. (2008). Flooding stress: acclimations and genetic diversity. Annu. Rev. Plant Biol. 59, 313-339. doi: 10.1146/annurev.arplant.59. 032607.092752

Barford, D. (2004). The role of cysteine residues as redox-sensitive regulatory switches. Curr. Opin. Struct. Biol. 14, 679-686. doi: 10.1016/j.sbi.2004.09.012

Baxter, C. J., Redestig, H., Schauer, N., Repsilber, D., Patil, K. R., Nielsen, J., et al. (2007). The metabolic response of heterotrophic Arabidopsis cells to oxidative stress. Plant Physiol. 143, 312-325. doi: 10.1104/pp.106.090431

Bedhomme, M., Adamo, M., Marchand, H. C., Couturier, J., Rouhier, N., Lemaire, S. D., et al. (2012). Glutathionylation of cytosolic glyceraldehyde-3-phosphate dehydrogenase from the model plant Arabidopsis thaliana is reversed by both 
glutaredoxins and thioredoxins in vitro. Biochem. J. 445, 337-347. doi: 10.1042/ BJ20120505

Bender, K. W., Wang, X. J., Cheng, G. B., Kim, H. S., Zielinski, R. E., and Huber, S. C. (2015). Glutaredoxin AtGRXC2 catalyses inhibitory glutathionylation of Arabidopsis BRI1-associated receptor-like kinase 1 (BAK1) in vitro. Biochem. J. 467, 399-413. doi: 10.1042/BJ20141403

Benhar, M., Forrester, M. T., and Stamler, J. S. (2009). Protein denitrosylation: enzymatic mechanisms and cellular functions. Nat. Rev. Mol. Cell Biol. 10:721. doi: $10.1038 / \mathrm{nrm} 2764$

Britto, P. J., Knipling, L., and Wolff, J. (2002). The local electrostatic environment determines cysteine reactivity of tubulin. J. Biol. Chem. 277, 29018-29027. doi: 10.1074/jbc.M204263200

Buchanan, B. B., Schürmann, P., Wolosiuk, R. A., and Jacquot, J.-P. (2002). The ferredoxin/thioredoxin system: from discovery to molecular structures and beyond. Photosynth. Res. 73, 215-222. doi: 10.1023/A:1020407432008

Camejo, D., Guzmán-Cedeño, Á., and Moreno, A. (2016). Reactive oxygen species, essential molecules, during plant-pathogen interactions. Plant Physiol. Biochem. 103, 10-23. doi: 10.1016/j.plaphy.2016.02.035

Carr, P. D., Verger, D., Ashton, A. R., and Ollis, D. L. (1999). Chloroplast NADPmalate dehydrogenase: structural basis of light-dependent regulation of activity by thiol oxidation and reduction. Struct. Fold. Des. 7, 461-475. doi: 10.1016/ s0969-2126(99)80058-6

Chang, T.-S., Jeong, W., Woo, H. A., Lee, S. M., Park, S., and Rhee, S. G. (2004). Characterization of mammalian sulfiredoxin and its reactivation of hyperoxidized peroxiredoxin through reduction of cysteine sulfinic acid in the active site to cysteine. J. Biol. Chem. 279, 50994-51001. doi: 10.1074/jbc. M409482200

Chen, J., Wu, F. H., Wang, W. H., Zheng, C. J., Lin, G. H., Dong, X. J., et al. (2011). Hydrogen sulphide enhances photosynthesis through promoting chloroplast biogenesis, photosynthetic enzyme expression, and thiol redox modification in Spinacia oleracea seedlings. J. Exp. Bot. 62, 4481-4493. doi: 10.1093/jxb/err145

Chen, R. D. (1998). Plant NADP-dependent isocitrate dehydrogenases are predominantly localized in the cytosol. Planta 207, 280-285. doi: 10.1007/ s004250050484

Chen, Z. J., Sun, L. L., Liu, P. D., Liu, G. D., Tian, J., and Liao, H. (2015). Malate synthesis and secretion mediated by a manganese-enhanced malate dehydrogenase confers superior manganese tolerance in Stylosanthes guianensis. Plant Physiol. 167, 176-188. doi: 10.1104/pp.114.251017

Chivasa, S., and Carr, J. P. (1998). Cyanide restores N gene-mediated resistance to tobacco mosaic virus in transgenic tobacco expressing salicylic acid hydroxylase. Plant Cell 10, 1489-1498. doi: 10.2307/3870613

Choi, H.-J., Kim, S.-J., Mukhopadhyay, P., Cho, S., Woo, J.-R., Storz, G., et al. (2001). Structural basis of the redox switch in the OxyR transcription factor. Cell 105, 103-113. doi: 10.1016/S0092-8674(01)00300-2

Corpas, F. J., and Barroso, J. B. (2014). NADPH-generating dehydrogenases: their role in the mechanism of protection against nitro-oxidative stress induced by adverse environmental conditions. Front. Environ. Sci. 2:55. doi: 10.3389/fenvs. 2014.00055

Corpas, F. J., Leterrier, M., Valderrama, R., Airaki, M., Chaki, M., Palma, J. M., et al. (2011). Nitric oxide imbalance provokes a nitrosative response in plants under abiotic stress. Plant Sci. 181, 604-611. doi: 10.1016/j.plantsci.2011. 04.005

Cotgreave, I. A., Gerdes, R., Schuppe-Koistinen, I., and Lind, C. (2002). S-glutathionylation of glyceraldehyde-3-phosphate dehydrogenase: role of thiol oxidation and catalysis by glutaredoxin. Methods Enzymol. 348, 175-182. doi: 10.1016/s0076-6879(02)48636-3

Couturier, J., Chibani, K., Jacquot, J.-P., and Rouhier, N. (2013). Cysteine-based redox regulation and signaling in plants. Front. Plant Sci. 4:105. doi: 10.3389/ fpls.2013.00105

Da Silva, D., Lachaud, C., Cotelle, V., Brière, C., Grat, S., Mazars, C., et al. (2011). Nitric oxide production is not required for dihydrosphingosine-induced cell death in tobacco BY-2 cells. Plant Signal. Behav. 6, 736-739. doi: 10.4161/psb.6. 5.15126

del Rio, L. A. (2015). ROS and RNS in plant physiology: an overview. J. Exp. Bot. 66, 2827-2837. doi: 10.1093/jxb/erv099

Demidchik, V. (2015). Mechanisms of oxidative stress in plants: from classical chemistry to cell biology. Environ. Exp. Bot. 109, 212-228. doi: 10.1016/j. envexpbot.2014.06.021
Dietz, K. J. (2003). Plant peroxiredoxins. Annual Rev. Plant Biol. 54, 93-107. doi: 10.1146/annurev.arplant.54.031902.134934

Dixon, D. P., Skipsey, M., Grundy, N. M., and Edwards, R. (2005). Stress-induced protein S-glutathionylation in Arabidopsis. Plant Physiol. 138, 2233-2244. doi: 10.1104/pp.104.058917

Domingos, P., Prado, A. M., Wong, A., Gehring, C., and Feijo, J. A. (2015). Nitric oxide: a multitasked signaling gas in plants. Mol. Plant 8, 506-520. doi: 10.1016/j.molp.2014.12.010

Dordas, C., Hasinoff, B. B., Igamberdiev, A. U., Manac'h, N., Rivoal, J., and Hill, R. D. (2003a). Expression of a stress-induced hemoglobin affects NO levels produced by alfalfa root cultures under hypoxic stress. Plant J. 35, 763-770.

Dordas, C., Rivoal, J., and Hill, R. D. (2003b). Plant haemoglobins, nitric oxide and hypoxic stress. Ann. Bot. 91, 173-178. doi: 10.1093/aob/mcf115

Dordas, C., Hasinoff, B. B., Rivoal, J., and Hill, R. D. (2004). Class-1 hemoglobins, nitrate and NO levels in anoxic maize cell-suspension cultures. Planta 219, 66-72. doi: 10.1007/s00425-004-1212-y

Dorion, S., Clendenning, A., Jeukens, J., Salas, J., Parveen, N., Haner, A., et al. (2012). A large decrease of cytosolic triosephosphate isomerase in transgenic potato roots affects the distribution of carbon in primary metabolism. Planta 236, 1177-1190. doi: 10.1007/s00425-012-1675-1

Dumont, S., Bykova, N. V., Khaou, A., Besserour, Y., Maude, D., and Rivoal, J. (2018). Arabidopsis thaliana alcohol dehydrogenase is differently affected by several redox modifications. PLoS One 13:e0204530. doi: 10.1371/journal.pone. 0204530

Dumont, S., Bykova, N. V., Pelletier, G., Dorion, S., and Rivoal, J. (2016). Cytosolic triosephosphate isomerase from Arabidopsis thaliana is reversibly modified by glutathione on Cysteines 127 and 218. Front. Plant Sci. 7:1942. doi: 10.3389/fpls. 2016.01942

Dyson, B. C., Miller, M. A., Feil, R., Rattray, N., Bowsher, C., Goodacre, R., et al. (2016). FUM2, a cytosolic fumarase, is essential for acclimation to low temperature in Arabidopsis thaliana. Plant Physiol. 172, 118-127. doi: 10.1104/ pp.16.00852

Eprintsev, A. T., Fedorin, D. N., Nikitina, M. V., and Igamberdiev, A. U. (2015). Expression and properties of the mitochondrial and cytosolic forms of aconitase in maize scutellum. J. Plant Physiol. 181, 14-19. doi: 10.1016/j.plph.2015. 03.012

Fares, A., Rossignol, M., and Peltier, J.-B. (2011). Proteomics investigation of endogenous S-nitrosylation in Arabidopsis. Biochem. Biophys. Res. Commun. 416, 331-336. doi: 10.1016/j.bbrc.2011.11.036

Finkel, T. (2000). Redox-dependent signal transduction. FEBS Lett. 476, 52-54. doi: 10.1016/S0014-5793(00)01669-0

Finkel, T. (2012). From sulfenylation to sulfhydration: what a thiolate needs to tolerate. Sci. Signal. 5:e10. doi: 10.1126/scisignal.2002943

Forman, H. J., Maiorino, M., and Ursini, F. (2010). Signaling functions of reactive oxygen species. Biochemistry 49, 835-842. doi: 10.1021/bi9020378

Foyer, C. H., and Noctor, G. (2009). Redox regulation in photosynthetic organisms: signaling, acclimation, and practical implications. Antioxid. Redox Signal. 11, 861-905. doi: 10.1089/ars.2008.2177

Fryer, M. J. (1992). The antioxidant effects of thylakoid vitamin-e(alphatocopherol). Plant Cell Environ. 15, 381-392. doi: 10.1111/j.1365-3040.1992. tb00988.x

Fu, Y., Tang, J., Yao, G.-F., Huang, Z.-Q., Li, Y.-H., Han, Z., et al. (2018). Central role of adenosine 5'-phosphosulfate reductase in the control of plant hydrogen sulfide metabolism. Front. Plant Sci. 9:1404. doi: 10.3389/fpls.2018.01404

Galvez, S., and Gadal, P. (1995). On the function of the nadp-dependent isocitrate dehydrogenase isoenzymes in living organisms. Plant Sci. 105, 1-14. doi: 10. 1016/0168-9452(94)04041-e

Garagounis, C., Kostaki, K.-I., Hawkins, T. J., Cummins, I., Fricker, M. D., Hussey, P. J., et al. (2017). Microcompartmentation of cytosolic aldolase by interaction with the actin cytoskeleton in Arabidopsis. J. Exp. Bot. 68, 885-898. doi: 10.1093/ jxb/erx015

Garcia, J. A., Minard, K. I., Lin, A.-P., and McAlister-Henn, L. (2009). Disulfide bond formation in yeast NAD+-specific isocitrate dehydrogenase. Biochemistry 48, 8869-8878. doi: 10.1021/bi900968a

Ghezzi, P., and Bonetto, V. (2003). Redox proteomics: identification of oxidatively modified proteins. Proteomics 3, 1145-1153. doi: 10.1002/pmic.200300435

Giegé, P., Heazlewood, J. L., Roessner-Tunali, U., Millar, A. H., Fernie, A. R., Leaver, C. J., et al. (2003). Enzymes of glycolysis are functionally associated 
with the mitochondrion in Arabidopsis cells. Plant Cell 15, 2140-2151. doi: $10.1105 /$ tpc. 012500

Gill, S. S., and Tuteja, N. (2010). Reactive oxygen species and antioxidant machinery in abiotic stress tolerance in crop plants. Plant Physiol. Biochem. 48, 909-930. doi: 10.1016/j.plaphy.2010.08.016

Graham, J. W., Williams, T. C., Morgan, M., Fernie, A. R., Ratcliffe, R. G., and Sweetlove, L. J. (2007). Glycolytic enzymes associate dynamically with mitochondria in response to respiratory demand and support substrate channeling. Plant Cell 19, 3723-3738. doi: 10.1105/tpc.107.053371

Groppa, M. D., Tomaro, M. L., and Benavides, M. P. (2001). Polyamines as protectors against cadmium or copper-induced oxidative damage in sunflower leaf discs. Plant Sci. 161, 481-488. doi: 10.1016/s0168-9452(01)00432-0

Guo, L., Devaiah, S. P., Narasimhan, R., Pan, X. Q., Zhang, Y. Y., Zhang, W. H., et al. (2012). Cytosolic glyceraldehyde-3-phosphate dehydrogenases interact with phospholipase D delta to transduce hydrogen peroxide signals in the Arabidopsis response to stress. Plant Cell 24, 2200-2212. doi: 10.1105/tpc.111. 094946

Guo, L., Ma, F. F., Wei, F., Fanella, B., Allen, D. K., and Wang, X. M. (2014). Cytosolic Phosphorylating glyceraldehyde-3-phosphate dehydrogenases affect Arabidopsis cellular metabolism and promote seed oil accumulation. Plant Cell 26, 3023-3035. doi: 10.1105/tpc.114.126946

Gupta, K. J., and Igamberdiev, A. U. (2011). The anoxic plant mitochondrion as a nitrite: NO reductase. Mitochondrion 11, 537-543. doi: 10.1016/j.mito.2011. 03.005

Gupta, K. J., and Kaiser, W. M. (2010). Production and scavenging of nitric oxide by barley root mitochondria. Plant Cell Physiol. 51, 576-584. doi: 10.1093/pcp/ pcq022

Gupta, K. J., Shah, J. K., Brotman, Y., Jahnke, K., Willmitzer, L., Kaiser, W. M., et al. (2012). Inhibition of aconitase by nitric oxide leads to induction of the alternative oxidase and to a shift of metabolism towards biosynthesis of amino acids. J. Exp. Bot. 63, 1773-1784. doi: 10.1093/jxb/ers053

Hara, M. R., Agrawal, N., Kim, S. F., Cascio, M. B., Fujimuro, M., Ozeki, Y., et al. (2005). S-nitrosylated GAPDH initiates apoptotic cell death by nuclear translocation following Siah1 binding. Nat. Cell Biol. 7, 665-674. doi: 10.1038/ ncb 1268

Hara, S., Motohashi, K., Arisaka, F., Romano, P. G. N., Hosoya-Matsuda, N., Kikuchi, N., et al. (2006). Thioredoxin-h1 reduces and reactivates the oxidized cytosolic malate dehydrogenase dimer in higher plants. J. Biol. Chem. 281, 32065-32071. doi: 10.1074/jbc.M605784200

Hardin, S. C., Larue, C. T., Oh, M. H., Jain, V., and Huber, S. C. (2009). Coupling oxidative signals to protein phosphorylation via methionine oxidation in Arabidopsis. Biochem. J. 422, 305-312. doi: 10.1042/bj20090764

Henry, E., Fung, N., Liu, J., Drakakaki, G., and Coaker, G. (2015). Beyond glycolysis: GAPDHs are multi-functional enzymes involved in regulation of ROS, autophagy, and plant immune responses. PLoS Genetics 11:e1005199. doi: 10.1371/journal.pgen.1005199

Hernandez, I., Alegre, L., Van Breusegem, F., and Munne-Bosch, S. (2009). How relevant are flavonoids as antioxidants in plants? Trends Plant Sci. 14, 125-132. doi: $10.1016 /$ j.tplants.2008.12.003

Hildebrandt, T., Knuesting, J., Berndt, C., Morgan, B., and Scheibe, R. (2015). Cytosolic thiol switches regulating basic cellular functions: GAPDH as an information hub? Biol. Chem. 396, 523-537. doi: 10.1515/hsz-2014-0295

Holtgrefe, S., Gohlke, J., Starmann, J., Druce, S., Klocke, S., Altmann, B., et al. (2008). Regulation of plant cytosolic glyceraldehyde 3-phosphate dehydrogenase isoforms by thiol modifications. Physiol. Plant. 133, 211-228. doi: 10.1111/j.1399-3054.2008.01066.x

Hu, J., Huang, X., Chen, L., Sun, X., Lu, C., Zhang, L., et al. (2015). Site-specific nitrosoproteomic identification of endogenously S-nitrosylated proteins in Arabidopsis. Plant Physiol. 167, 1731-1746. doi: 10.1104/pp.15.00026

Huang, J. J., Niazi, A. K., Young, D., Rosado, L. A., Vertommen, D., Bodra, N., et al. (2018). Self-protection of cytosolic malate dehydrogenase against oxidative stress in Arabidopsis. J. Exp. Bot. 69, 3491-3505. doi: 10.1093/jxb/ erx396

Igamberdiev, A. U., Bykova, N. V., Shah, J. K., and Hill, R. D. (2010). Anoxic nitric oxide cycling in plants: participating reactions and possible mechanisms. Physiol. Plant. 138, 393-404. doi: 10.1111/j.1399-3054.2009.01314.x

Ishikawa, T., Takahara, K., Hirabayashi, T., Matsumura, H., Fujisawa, S., Terauchi, R., et al. (2009). Metabolome analysis of response to oxidative stress in rice suspension cells overexpressing cell death suppressor Bax inhibitor-1. Plant Cell Physiol. 51, 9-20. doi: 10.1093/pcp/pcp162

Ishikawa, T., Uchimiya, H., and Kawai-Yamada, M. (2013). The role of plant bax inhibitor-1 in suppressing H2O2-induced cell death. Methods Enzymol. 527, 239-256. doi: 10.1016/b978-0-12-405882-8.00013-1

Ismond, K. P., Dolferus, R., De Pauw, M., Dennis, E. S., and Good, A. G. (2003). Enhanced low oxygen survival in Arabidopsis through increased metabolic flux in the fermentative pathway. Plant Physiol. 132, 1292-1302. doi: 10.1104/pp. 103.022244

Ito, H., Iwabuchi, M., and Ogawa, K. (2003). The sugar-metabolic enzymes aldolase and triose-phosphate isomerase are targets of glutathionylation in Arabidopsis thaliana: detection using biotinylated glutathione. Plant Cell Physiol. 44, 655-660. doi: 10.1093/pcp/pcg098

Jarosz, A. P., Wei, W. L., Gauld, J. W., Auld, J., Ozcan, F., Aslan, M., et al. (2015). Glyceraldehyde 3-phosphate dehydrogenase (GAPDH) is inactivated by S-sulfuration in vitro. Free Radic. Biol. Med. 89, 512-521. doi: 10.1016/j. freeradbiomed.2015.09.007

Kawai-Yamada, M., Ohori, Y., and Uchimiya, H. (2004). Dissection of Arabidopsis bax inhibitor-1 suppressing bax-, hydrogen peroxide-, and salicylic acidinduced cell death. Plant Cell 16, 21-32. doi: 10.1105/tpc.014613

Kolbe, A., Oliver, S. N., Fernie, A. R., Stitt, M., van Dongen, J. T., and Geigenberger, P. (2006). Combined transcript and metabolite profiling of Arabidopsis leaves reveals fundamental effects of the thiol-disulfide status on plant metabolism. Plant Physiol. 141, 412-422. doi: 10.1104/pp.106.081208

Kusano, M., Tohge, T., Fukushima, A., Kobayashi, M., Hayashi, N., Otsuki, H., et al. (2011). Metabolomics reveals comprehensive reprogramming involving two independent metabolic responses of Arabidopsis to UV-B light. Plant J. 67, 354-369. doi: 10.1111/j.1365-313X.2011.04599.x

Lachaud, C., Da Silva, D., Amelot, N., Beziat, C., Briere, C., Cotelle, V., et al. (2011). Dihydrosphingosine-induced programmed cell death in tobacco BY-2 cells is independent of $\mathrm{H} 2 \mathrm{O} 2$ production. Mol. Plant 4, 310-318. doi: 10.1093/mp/ ssq077

Lachaud, C., Da Silva, D., Cotelle, V., Thuleau, P., Xiong, T. C., Jauneau, A., et al. (2010). Nuclear calcium controls the apoptotic-like cell death induced by D-erythro-sphinganine in tobacco cells. Cell Calcium 47, 92-100. doi: 10.1016/ j.ceca.2009.11.011

Larson, R. A. (1988). The antioxidants of higher-plants. Phytochemistry 27, 969-978. doi: 10.1016/0031-9422(88)80254-1

Lehmann, M., Laxa, M., Sweetlove, L. J., Fernie, A. R., and Obata, T. (2012). Metabolic recovery of Arabidopsis thaliana roots following cessation of oxidative stress. Metabolomics 8, 143-153. doi: 10.1007/s11306-011-0296-1

Lehmann, M., Schwarzländer, M., Obata, T., Sirikantaramas, S., Burow, M., Olsen, C. E., et al. (2009). The metabolic response of Arabidopsis roots to oxidative stress is distinct from that of heterotrophic cells in culture and highlights a complex relationship between the levels of transcripts, metabolites, and flux. Mol. Plant 2, 390-406. doi: 10.1093/mp/ssn080

Lemaire, S. D., Quesada, A., Merchan, F., Corral, J. M., Igeno, M. I., Keryer, E., et al. (2005). NADP-malate dehydrogenase from unicellular green alga Chlamydomonas reinhardtii. A first step toward redox regulation. Plant Physiol. 137, 514-521. doi: 10.1104/pp.104.052670

Leterrier, M., Barroso, J. B., Palma, J. M., and Corpas, F. J. (2012). Cytosolic NADP-isocitrate dehydrogenase in Arabidopsis leaves and roots. Biol. Plant. 56, 705-710. doi: 10.1007/s10535-012-0244-6

Lindermayr, C., Saalbach, G., and Durner, J. (2005). Proteomic identification of S-nitrosylated proteins in Arabidopsis. Plant Physiol. 137, 921-930. doi: 10.1104/ pp.104.058719

Liu, P., Zhang, H. M., Wang, H., and Xia, Y. J. (2014). Identification of redox-sensitive cysteines in the Arabidopsis proteome using OxiTRAQ, a quantitative redox proteomics method. Proteomics 14, 750-762. doi: 10.1002/ pmic.201300307

Margis, R., Dunand, C., Teixeira, F. K., and Margis-Pinheiro, M. (2008). Glutathione peroxidase family - an evolutionary overview. FEBS J. 275, 3959-3970. doi: 10.1111/j.1742-4658.2008.06542.x

Marino, D., Dunand, C., Puppo, A., and Pauly, N. (2012). A burst of plant NADPH oxidases. Trends Plant Sci. 17, 9-15. doi: 10.1016/j.tplants.2011. 10.001

Meyer, A. J., Brach, T., Marty, L., Kreye, S., Rouhier, N., Jacquot, J. P., et al. (2007). Redox-sensitive GFP in Arabidopsis thaliana is a quantitative biosensor for the 
redox potential of the cellular glutathione redox buffer. Plant J. 52, 973-986. doi: 10.1111/j.1365-313X.2007.03280.x

Mhamdi, A., Queval, G., Chaouch, S., Vanderauwera, S., Van Breusegem, F., and Noctor, G. (2010). Catalase function in plants: a focus on Arabidopsis mutants as stress-mimic models. J. Exp. Bot. 61, 4197-4220. doi: 10.1093/jxb/erq282

Michelet, L., Zaffagnini, M., Marchand, C., Collin, V., Decottignies, P., Tsan, P., et al. (2005). Glutathionylation of chloroplast thioredoxin $\mathrm{f}$ is a redox signaling mechanism in plants. Proc. Natl. Acad. Sci. U.S.A. 102, 16478-16483. doi: 10. 1073/pnas.0507498102

Michelet, L., Zaffagnini, M., Morisse, S., Sparla, F., Pérez-Pérez, M. E., Francia, F., et al. (2013). Redox regulation of the calvin-benson cycle: something old, something new. Front. Plant Sci. 4:470. doi: 10.3389/fpls.2013.00470

Michelet, L., Zaffagnini, M., Vanacker, H., Le Marechal, P., Marchand, C., Schroda, M., et al. (2008). In vivo targets of S-thiolation in Chlamydomonas reinhardtii. J. Biol. Chem. 283, 21571-21578. doi: 10.1074/jbc.M802331200

MiginiacMaslow, M., Issakidis, E., Lemaire, M., Ruelland, E., Jacquot, J. P., and Decottignies, P. (1997). Light-dependent activation of NADP-malate dehydrogenase: a complex process. Aust. J. Plant Physiol. 24, 529-542. doi: $10.1071 /$ pp97004

Mittler, R. (2002). Oxidative stress, antioxidants and stress tolerance. Trends Plant Sci. 7, 405-410. doi: 10.1016/S1360-1385(02)02312-9

Moeder, W., Del Pozo, O., Navarre, D. A., Martin, G. B., and Klessig, D. F. (2007). Aconitase plays a role in regulating resistance to oxidative stress and cell death in Arabidopsis and Nicotiana benthamiana. Plant Mol. Biol. 63, 273-287. doi: 10.1007/s11103-006-9087-x

Mohr, S., Hallak, H., de Boitte, A., Lapetina, E. G., and Brüne, B. (1999). Nitric oxide-induced S-glutathionylation and inactivation of glyceraldehyde-3phosphate dehydrogenase. J. Biol. Chem. 274, 9427-9430. doi: 10.1074/jbc.274. 14.9427

Møller, I. M., Jensen, P. E., and Hansson, A. (2007). Oxidative modifications to cellular components in plants. Annu. Rev. Plant Biol. 58, 459-481. doi: 10.1146/ annurev.arplant.58.032806.103946

Morigasaki, S., Shimada, K., Ikner, A., Yanagida, M., and Shiozaki, K. (2008). Glycolytic enzyme GAPDH promotes peroxide stress signaling through multistep phosphorelay to a MAPK cascade. Mol. Cell 30, 108-113. doi: 10. 1016/j.molcel.2008.01.017

Murphy, A. M., Chivasa, S., Singh, D. P., and Carr, J. P. (1999). Salicylic acidinduced resistance to viruses and other pathogens: a parting of the ways? Trends Plant Sci. 4, 155-160.

Mustafa, A. K., Gadalla, M. M., Sen, N., Kim, S., Mu, W. T., Gazi, S. K., et al. (2009). H2S signals through protein s-sulfhydration. Sci. Signal. 2:ra72. doi: 10.1126/scisignal.2000464

Navarre, D. A., Wendehenne, D., Durner, J., Noad, R., and Klessig, D. F. (2000). Nitric oxide modulates the activity of tobacco aconitase. Plant Physiol. 122, 573-582. doi: 10.1104/pp.122.2.573

Noctor, G., and Foyer, C. H. (1998). Ascorbate and glutathione: keeping active oxygen under control. Annu. Rev. Plant Physiol. Plant Mol. Biol. 49, 249-279. doi: 10.1146/annurev.arplant.49.1.249

Noctor, G., Reichheld, J.-P., and Foyer, C. H. (2017). ROS-related redox regulation and signaling in plants. Sem. Cell Dev. Biol. 80, 3-12. doi: 10.1016/j.semcdb. 2017.07.013

Noguera-Mazon, V., Lemoine, J., Walker, O., Rouhier, N., Salvador, A., Jacquot, J. P., et al. (2006). Glutathionylation induces the dissociation of 1-Cys D-peroxiredoxin non-covalent homodimer. J. Biol. Chem. 281, 31736-31742. doi: $10.1074 /$ jbc.M602188200

Obata, T., Matthes, A., Koszior, S., Lehmann, M., Araújo, W. L., Bock, R., et al. (2011). Alteration of mitochondrial protein complexes in relation to metabolic regulation under short-term oxidative stress in Arabidopsis seedlings. Phytochemistry 72, 1081-1091. doi: 10.1016/j.phytochem.2010.11.003

Ozturk, L., and Demir, Y. (2002). In vivo and in vitro protective role of proline. Plant Growth Regul. 38, 259-264. doi: 10.1023/a:1021579713832

Padgett, C. M., and Whorton, A. R. (1995). S-nitrosoglutathione reversibly inhibits gapdh by s-nitrosylation. Am. J. Physiol. Cell Physiol. 269, C739-C749. doi: 10.1152/ajpcell.1995.269.3.C739

Paul, B. D., and Snyder, S. H. (2012). H2S signalling through protein sulfhydration and beyond. Nat. Rev. Mol. Cell Biol. 13, 499-507. doi: 10.1038/nrm3391

Piattoni, C. V., Ferrero, D. M. L., Dellaferrera, I., Vegetti, A., and Iglesias, A. A. (2017). Cytosolic glyceraldehyde-3-phosphate dehydrogenase is phosphorylated during seed development. Front. Plant Sci. 8:522. doi: 10.3389/fpls.2017.00522

Plaxton, W. C. (1996). The organization and regulation of plant glycolysis. Ann. Rev. Plant Physiol. Plant Mol. Biol. 47, 185-214. doi: 10.1146/annurev.arplant. 47.1.185

Poole, L. B., Karplus, P. A., and Claiborne, A. (2004). Protein sulfenic acids in redox signaling. Ann. Rev. Pharmacol. Toxicol. 44, 325-347. doi: 10.1146/annurev. pharmtox.44.101802.121735

Pracharoenwattana, I., Cornah, J. E., and Smith, S. M. (2005). Arabidopsis peroxisomal citrate synthase is required for fatty acid respiration and seed germination. Plant Cell 17, 2037-2048. doi: 10.1105/tpc.105.031856

Pracharoenwattana, I., Zhou, W., Keech, O., Francisco, P. B., Udomchalothorn, T., Tschoep, H., et al. (2010). Arabidopsis has a cytosolic fumarase required for the massive allocation of photosynthate into fumaric acid and for rapid plant growth on high nitrogen. Plant J. 62, 785-795. doi: 10.1111/j.1365-313X.2010. 04189.x

Puyaubert, J., Fares, A., Reze, N., Peltier, J. B., and Baudouin, E. (2014). Identification of endogenously S-nitrosylated proteins in Arabidopsis plantlets: Effect of cold stress on cysteine nitrosylation level. Plant Sci. 215, 150-156. doi: 10.1016/j.plantsci.2013.10.014

Ralser, M., Wamelink, M. M., Kowald, A., Gerisch, B., Heeren, G., Struys, E. A., et al. (2007). Dynamic rerouting of the carbohydrate flux is key to counteracting oxidative stress. J. Biol. 6, 301-312. doi: 10.1186/jbiol61

Rao, R. S. P., Xu, D., Thelen, J. J., and Miernyk, J. A. (2013). Circles within circles: crosstalk between protein Ser/Thr/Tyr-phosphorylation and met oxidation. BMC Bioinformatics 14:S14. doi: 10.1186/1471-2105-14-s14-s14

Romero-Puertas, M. C., Rodriguez-Serrano, M., and Sandalio, L. M. (2013). Protein S-nitrosylation in plants under abiotic stress: an overview. Front. Plant Sci. 4:373. doi: 10.3389/fpls.2013.00373

Rouhier, N., Lemaire, S. D., and Jacquot, J.-P. (2008). The role of glutathione in photosynthetic organisms: emerging functions for glutaredoxins and glutathionylation. Annu. Rev. Plant Biol. 59, 143-166. doi: 10.1146/annurev. arplant.59.032607.092811

Ruelland, E., and Miginiac-Maslow, M. (1999). Regulation of chloroplast enzyme activities by thioredoxins: activation or relief from inhibition? Trends Plant Sci. $4,136-141$.

Scheibe, R. (2004). Malate valves to balance cellular energy supply. Physiol. Plant. 120, 21-26. doi: 10.1111/j.0031-9317.2004.0222.x

Schmidtmann, E., König, A.-C., Orwat, A., Leister, D., Hartl, M., and Finkemeier, I. (2014). Redox regulation of Arabidopsis mitochondrial citrate synthase. Mol. Plant 7, 156-169. doi: $10.1093 / \mathrm{mp} / \mathrm{sst} 144$

Schneider, M., Knuesting, J., Birkholz, O., Heinisch, J. J., and Scheibe, R. (2018). Cytosolic GAPDH as a redox-dependent regulator of energy metabolism. BMC Plant Biol. 18:184. doi: 10.1186/s12870-018-1390-6

Schwarzländer, M., Fricker, M., Müller, C., Marty, L., Brach, T., Novak, J., et al. (2008). Confocal imaging of glutathione redox potential in living plant cells. J. Microscopy 231, 299-316. doi: 10.1111/j.1365-2818.2008.02030.x

Sen, N., Paul, B. D., Gadalla, M. M., Mustafa, A. K., Sen, T., Xu, R., et al. (2012). Hydrogen sulfide-linked sulfhydration of NF- $\mathrm{KB}$ mediates its antiapoptotic actions. Mol. Cell 45, 13-24. doi: 10.1016/j.molcel.2011.10.021

Seregélyes, C., Barna, B., Hennig, J., Konopka, D., Pasternak, T. P., Lukács, N., et al. (2003). Phytoglobins can interfere with nitric oxide functions during plant growth and pathogenic responses: a transgenic approach. Plant Sci. 165, 541-550. doi: 10.1016/S0168-9452(03)00213-9

Sharma, P., Jha, A. B., Dubey, R. S., and Pessarakli, M. (2012). Reactive oxygen species, oxidative damage, and antioxidative defense mechanism in plants under stressful conditions. J. Bot. 2012:217037. doi: 10.1155/2012/217037

Shen, J. J., Qiao, Z. J., Xing, T. J., Zhang, L. P., Liang, Y. L., Jin, Z. P., et al. (2012). Cadmium toxicity is alleviated by AtLCD and AtDCD in Escherichia coli. J. Appl. Microbiol. 113, 1130-1138. doi: 10.1111/j.1365-2672.2012.05408.x

Shen, J. J., Xing, T. J., Yuan, H. H., Liu, Z. Q., Jin, Z. P., Zhang, L. P., et al. (2013). Hydrogen sulfide improves drought tolerance in Arabidopsis thaliana by MicroRNA expressions. PLoS One 8:e77047. doi: 10.1371/journal.pone.0077047

Sies, H., Berndt, C., and Jones, D. P. (2017). Oxidative stress. Annu. Rev. Biochem. 86, 715-748. doi: 10.1146/annurev-biochem-061516-045037

Skryhan, K., Gurrieri, L., Sparla, F., Trost, P., and Blennow, A. (2018). Redox regulation of starch metabolism. Front. Plant Sci. 9:1344. doi: 10.3389/fpls.2018. 01344 
Smirnoff, N., and Cumbes, Q. J. (1989). Hydroxyl radical scavenging activity of compatible solutes. Phytochemistry 28, 1057-1060. doi: 10.1016/0031-9422(89) 80182-7

Stevens, F. J., Li, A. D., Lateef, S. S., and Anderson, L. E. (1997). Identification of potential inter-domain disulfides in three higher plant mitochondrial citrate synthases: paradoxical differences in redox-sensitivity as compared with the animal enzyme. Photosynth. Res. 54, 185-197. doi: 10.1023/a:1005991423503

Strommer, J. (2011). The plant ADH gene family. Plant J. 66, 128-142. doi: 10.1111/ j.1365-313X.2010.04458.x

Sweetlove, L., Heazlewood, J., Herald, V., Holtzapffel, R., Day, D., Leaver, C., et al. (2002). The impact of oxidative stress on Arabidopsis mitochondria. Plant J. 32, 891-904. doi: 10.1046/j.1365-313X.2002.01474.x

Taylor, A. B., Hu, G., Hart, P. J., and McAlister-Henn, L. (2008). Allosteric motions in structures of yeast NAD+-specific isocitrate dehydrogenase. J. Biol. Chem. 283, 10872-10880. doi: 10.1074/jbc.M708719200

Tesfaye, M., Temple, S. J., Allan, D. L., Vance, C. P., and Samac, D. A. (2001). Overexpression of malate dehydrogenase in transgenic alfalfa enhances organic acid synthesis and confers tolerance to aluminum. Plant Physiol. 127, 1836-1844. doi: 10.1104/pp.010376

Testard, A., Da Silva, D., Ormancey, M., Pichereaux, C., Pouzet, C., Jauneau, A., et al. (2016). Calcium- and nitric oxide-dependent nuclear accumulation of cytosolic glyceraldehyde-3-phosphate dehydrogenase in response to long chain bases in tobacco by-2 cells. Plant Cell Physiol. 57, 2221-2231. doi: 10.1093/pcp/ pcw137

Thannickal, V. J., and Fanburg, B. L. (2000). Reactive oxygen species in cell signaling. Am. J. Physiol. Lung Cell. Mol. Physiol. 279, L1005-L1028. doi: 10. 1152/ajplung.2000.279.6.L1005

Tripathy, B. C., and Oelmüller, R. (2012). Reactive oxygen species generation and signaling in plants. Plant Signal. Behav. 7, 1621-1633. doi: 10.4161/psb.22455

Troncoso-Ponce, M., Rivoal, J., Dorion, S., Sánchez, R., Venegas-Calerón, M., Moreno-Pérez, A., et al. (2018). Molecular and biochemical characterization of the sunflower (Helianthus annuus L.) cytosolic and plastidial enolases in relation to seed development. Plant Sci. 272, 117-130. doi: 10.1016/j.plantsci. 2018.04.007

Umbreen, S., Lubega, J., Cui, B. M., Pan, Q. N., Jiang, J. H., and Loake, G. J. (2018). Specificity in nitric oxide signalling. J. Exp. Bot. 69, 3439-3448. doi: $10.1093 /$ jxb/ery184

Valancin, A., Srinivasan, B., Rivoal, J., and Jolicoeur, M. (2013). Analyzing the effect of decreasing cytosolic triosephosphate isomerase on Solanum tuberosum hairy root cells using a kineticmetabolic model. Biotechnol. Bioeng. 110, 924-935. doi: 10.1002/bit.24747

van der Linde, K., Gutsche, N., Leffers, H.-M., Lindermayr, C., Müller, B., Holtgrefe, S., et al. (2011). Regulation of plant cytosolic aldolase functions by redox-modifications. Plant Physiol. Biochem. 49, 946-957. doi: 10.1016/j. plaphy.2011.06.009

Vanlerberghe, G. C., and Mclntosh, L. (1996). Signals regulating the expression of the nuclear gene encoding alternative oxidase of plant mitochondria. Plant Physiol. 111, 589-595.

Verniquet, F., Gaillard, J., Neuburger, M., and Douce, R. (1991). Rapid inactivation of plant aconitase by hydrogen peroxide. Biochem. J. 276, 643-648.

Vescovi, M., Zaffagnini, M., Festa, M., Trost, P., Lo Schiavo, F., and Costa, A. (2013). Nuclear accumulation of cytosolic glyceraldehyde-3phosphate dehydrogenase in cadmium-stressed Arabidopsis Roots. Plant Physiol. 162, 333-346. doi: 10.1104/pp.113.215194

Wang, H., Wang, S. B., Lu, Y. Q., Avarez, S., Hicks, L. M., Ge, X., et al. (2012). Proteomic analysis of early-responsive redox-sensitive proteins in Arabidopsis. J. Proteome Res. 11, 412-424. doi: 10.1021/pr200918f

Wang, Q. J., Sun, H., Dong, Q. L., Sun, T. Y., Jin, Z. X., Hao, Y. J., et al. (2016). The enhancement of tolerance to salt and cold stresses by modifying the redox state and salicylic acid content via the cytosolic malate dehydrogenase gene in transgenic apple plants. Plant Biotechnol. J. 14, 1986-1997. doi: 10.1111/pbi. 12556

Wilson, I. D., Neill, S. J., and Hancock, J. T. (2008). Nitric oxide synthesis and signalling in plants. Plant Cell Environ. 31, 622-631.

Wojtera-Kwiczor, J., Gross, F., Leffers, H.-M., Kang, M., Schneider, M., and Scheibe, R. (2013). Transfer of a redox-signal through the cytosol by redoxdependent microcompartmentation of glycolytic enzymes at mitochondria and actin cytoskeleton. Front. Plant Sci. 3:284. doi: 10.3389/fpls.2012.00284
Woo, H. A., Jeong, W., Chang, T.-S., Park, K. J., Park, S. J., Yang, J. S., et al. (2005). Reduction of cysteine sulfinic acid by sulfiredoxin is specific to 2-cys peroxiredoxins. J. Biol. Chem. 280, 3125-3128.

Wurzinger, B., Mair, A., Fischer-Schrader, K., Nukarinen, E., Roustan, V., Weckwerth, W., et al. (2017). Redox state-dependent modulation of plant SnRK1 kinase activity differs from AMPK regulation in animals. FEBS Lett. 591, 3625-3636. doi: 10.1002/1873-3468.12852

Wurzinger, B., Nukarinen, E., Nagele, T., Weckwerth, W., and Teige, M. (2018). The SnRK1 kinase as central mediator of energy signaling between different organelles. Plant Physiol. 176, 1085-1094. doi: 10.1104/pp.17.01404

Yoshida, K., and Hisabori, T. (2014). Mitochondrial isocitrate dehydrogenase is inactivated upon oxidation and reactivated by thioredoxin-dependent reduction in Arabidopsis. Front. Environ. Sci. 2:38. doi: 10.3389/fenvs.2014. 00038

Yoshida, K., and Hisabori, T. (2016). Adenine nucleotide-dependent and redoxindependent control of mitochondrial malate dehydrogenase activity in Arabidopsis thaliana. Biochim. Biophys. Acta Bioenerg. 1857, 810-818. doi: 10. 1016/j.bbabio.2016.03.001

Yoshida, K., Noguchi, K., Motohashi, K., and Hisabori, T. (2013). Systematic exploration of thioredoxin target proteins in plant mitochondria. Plant Cell Physiol. 54, 875-892. doi: 10.1093/pcp/pct037

You, J., and Chan, Z. L. (2015). ROS regulation during abiotic stress responses in crop plants. Front. Plant Sci. 6:1092. doi: 10.3389/fpls.2015.01092

Zaffagnini, M., Bedhomme, M., Groni, H., Marchand, C. H., Puppo, C., Gontero, B., et al. (2012a). Glutathionylation in the photosynthetic model organism Chlamydomonas reinhardtii: a proteomic survey. Mol. Cell. Proteomics 11:M111.014142. doi: 10.1074/mcp.M111.014142

Zaffagnini, M., Bedhomme, M., Lemaire, S. D., and Trost, P. (2012b). The emerging roles of protein glutathionylation in chloroplasts. Plant Sci. 185, 86-96. doi: 10.1016/j.plantsci.2012.01.005

Zaffagnini, M., Bedhomme, M., Marchand, C. H., Morisse, S., Trost, P., and Lemaire, S. D. (2012c). Redox regulation in photosynthetic organisms: focus on glutathionylation. Antioxid. Redox Signal. 16, 567-586. doi: 10.1089/ars.2011. 4255

Zaffagnini, M., De Mia, M., Morisse, S., Di Giacinto, N., Marchand, C., Maes, A., et al. (2016). Protein S-nitrosylation in photosynthetic organisms: a comprehensive overview with future perspectives. Biochim. Biophys. Acta 1864, 952-966. doi: 10.1016/j.bbapap.2016.02.006

Zaffagnini, M., Fermani, S., Costa, A., Lemaire, S. D., and Trost, P. (2013a). Plant cytoplasmic GAPDH: redox post-translational modifications and moonlighting properties. Front. Plant Sci. 4:450. doi: 10.3389/fpls.2013.00450

Zaffagnini, M., Morisse, S., Bedhomme, M., Marchand, C. H., Festa, M., Rouhier, N., et al. (2013b). Mechanisms of nitrosylation and denitrosylation of cytoplasmic glyceraldehyde-3-phosphate dehydrogenase from Arabidopsis thaliana. J. Biol. Chem. 288, 22777-22789. doi: 10.1074/jbc.M113.475467

Zaffagnini, M., Fermani, S., Costa, A., Lemaire, S. D., and Trost, P. (2014). Plant cytoplasmic GAPDH: redox post-translational modifications and moonlighting properties. Front. Plant Sci. 4:450. doi: 10.3389/fpls.2013.00450

Zhang, H., Hu, L. Y., Hu, K. D., He, Y. D., Wang, S. H., and Luo, J. P. (2008). Hydrogen sulfide promotes wheat seed germination and alleviates oxidative damage against copper stress. J. Integr. Plant Biol. 50, 1518-1529. doi: 10.1111/ j.1744-7909.2008.00769.x

Zubimendi, J. P., Martinatto, A., Valacco, M. P., Moreno, S., Andreo, C. S., Drincovich, M. F., et al. (2018). The complex allosteric and redox regulation of the fumarate hydratase and malate dehydratase reactions of Arabidopsis thaliana Fumarase 1 and 2 gives clues for understanding the massive accumulation of fumarate. FEBS J. 285, 2205-2224. doi: 10.1111/febs.14483

Conflict of Interest Statement: The authors declare that the research was conducted in the absence of any commercial or financial relationships that could be construed as a potential conflict of interest.

Copyright (c) 2019 Dumont and Rivoal. This is an open-access article distributed under the terms of the Creative Commons Attribution License (CC BY). The use, distribution or reproduction in other forums is permitted, provided the original author(s) and the copyright owner(s) are credited and that the original publication in this journal is cited, in accordance with accepted academic practice. No use, distribution or reproduction is permitted which does not comply with these terms. 